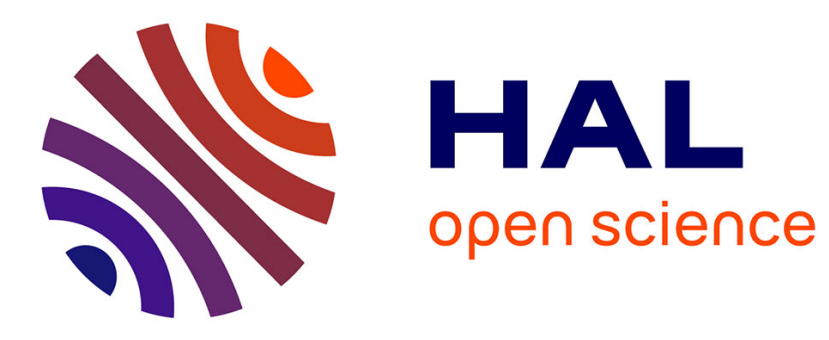

\title{
Photoactive Rose Bengal-based Latex via RAFT Emulsion Polymerization-Induced Self-Assembly
}

Charlène Boussiron, Mickael Le Béchec, Julia Sabalot, Sylvie

Lacombe-Lhoste, Maud Save

\section{- To cite this version:}

Charlène Boussiron, Mickael Le Béchec, Julia Sabalot, Sylvie Lacombe-Lhoste, Maud Save. Photoactive Rose Bengal-based Latex via RAFT Emulsion Polymerization-Induced Self-Assembly. Polymer Chemistry, 2021, 12, pp.134-147. 10.1039/D0PY01128B . hal-02979190

\section{HAL Id: hal-02979190 \\ https://hal.science/hal-02979190}

Submitted on 27 Oct 2020

HAL is a multi-disciplinary open access archive for the deposit and dissemination of scientific research documents, whether they are published or not. The documents may come from teaching and research institutions in France or abroad, or from public or private research centers.
L'archive ouverte pluridisciplinaire HAL, est destinée au dépôt et à la diffusion de documents scientifiques de niveau recherche, publiés ou non, émanant des établissements d'enseignement et de recherche français ou étrangers, des laboratoires publics ou privés. 


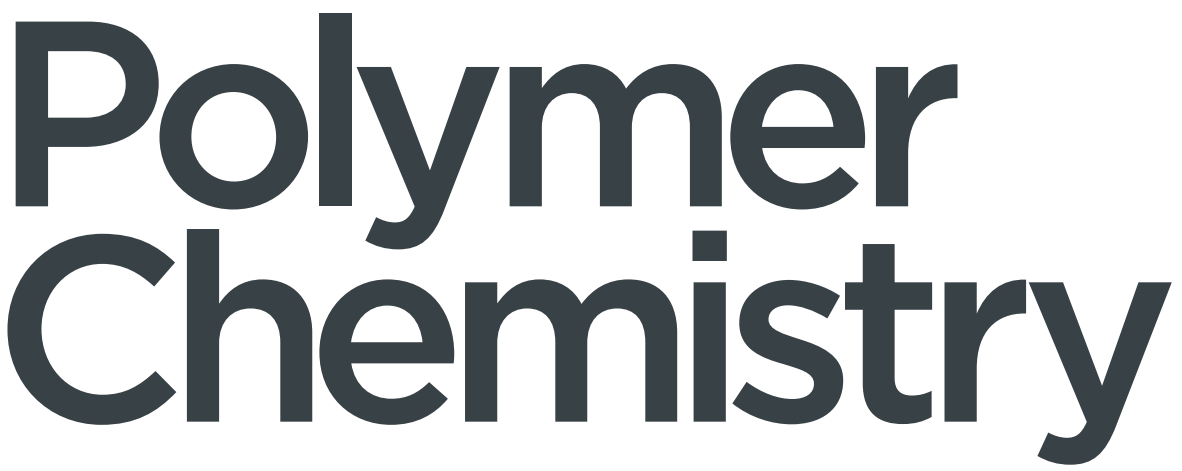

\section{Accepted Manuscript}

This article can be cited before page numbers have been issued, to do this please use: C. Boussiron, $M$.

LeBechec, J. Sabalot, S. Lacombe and M. Save, Polym. Chem., 2020, DOI: 10.1039/DOPY01128B.

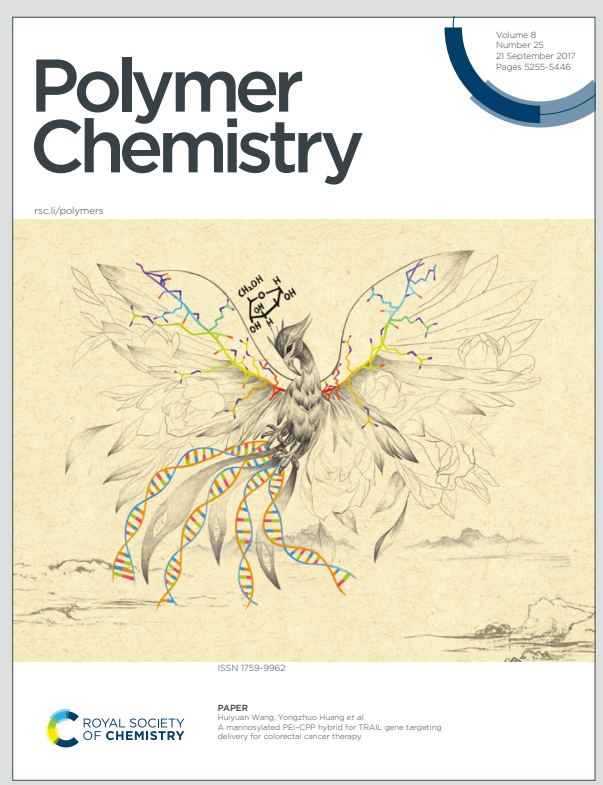

This is an Accepted Manuscript, which has been through the Royal Society of Chemistry peer review process and has been accepted for publication.

Accepted Manuscripts are published online shortly after acceptance, before technical editing, formatting and proof reading. Using this free service, authors can make their results available to the community, in citable form, before we publish the edited article. We will replace this Accepted Manuscript with the edited and formatted Advance Article as soon as it is available.

You can find more information about Accepted Manuscripts in the Information for Authors.

Please note that technical editing may introduce minor changes to the text and/or graphics, which may alter content. The journal's standard Terms \& Conditions and the Ethical guidelines still apply. In no event shall the Royal Society of Chemistry be held responsible for any errors or omissions in this Accepted Manuscript or any consequences arising from the use of any information it contains. 


\title{
Photoactive Rose Bengal-based Latex via RAFT Emulsion Polymerization- Induced Self-Assembly
}

Charlène Boussiron, Mickaël Le Bechec, Julia Sabalot, Sylvie Lacombe, Maud Save*

CNRS, University Pau \& Pays Adour, E2S UPPA, Institut des Sciences Analytiques et de Physico-Chimie pour l'Environnement et les Matériaux, IPREM, UMR5254, 64000, PAU, France.

Mail: maud.save@univ-pau.fr

$\dagger$ Electronic supplementary information (ESI) available.

\begin{abstract}
Copolymerization of acrylic acid (AA) with a photosensitizer-based comonomer by reversible addition fragmentation transfer (RAFT) polymerization produces reactive stabilizer for emulsion polymerization induced self-assembly (PISA). This polymerization in aqueous dispersed medium is a surfactant-free and solvent-free environmentally friendly process efficient to design dye-supported polymer colloids dispersed in water. Rose Bengal (RB) was selected as photosensitizer for the synthesis of two types of comonomers (MRB), vinyl benzyl Rose Bengal (VBRB) and ethyl acrylate Rose Bengal (EARB). The effect of the structure of MRB and solvent of RAFT copolymerization with AA was investigated. While VBRB induced strong retardation in 1-4-dioxane, to a larger extent compared to EARB, such retardation was overcome in polar dimethyl sulfoxide. The high level of chain end fidelity of PAA-based macromolecular chain transfer agent, as highlighted by UV-visible spectroscopy and proton NMR, allowed for efficient chain extension. Self-assembled amphiphilic block copolymers
\end{abstract}


synthesized by RAFT-mediated emulsion polymerization are stable monodisperse core-shell particles of 90 - $100 \mathrm{~nm}$ diameter. The shell is a hydrophilic poly(ammonium acrylate-co-MRB) statistical copolymer and the core is a film-forming poly(alkyl acrylate), either poly( $n$-butyl acrylate), or poly(ethyl acrylate) or poly(n-butyl acrylate-co-ethyl acrylate). A second synthetic route is proposed to label the particle core with photosensitizer. The interfacial singlet oxygen production was monitored by the degradation of furfuryl alcohol quencher under visible light irradiation. The average quantum yield of supported Rose Bengal $\left(\phi_{\Delta}=0.64 \pm 0.10\right)$ in a close range with free Rose Bengal in water $\left(\phi_{\Delta}=0.76 \pm 0.10\right)$ proves the photoactivity of photosensitizer-grafted waterborne latexes.

\section{Introduction}

Photosensitized reactions are defined as the absorption of a radiation by an organic molecular species, called photosensitizer, which induces the modification of another molecular species, either by electron transfer (type I mechanism) or by energy transfer (type II mechanism), with regeneration of the photosensitizer to its ground state without its chemical alteration. Singlet oxygen $\left({ }^{1} \mathrm{O}_{2}\right)$ is a powerful and selective oxidant mainly produced by energy transfer from the triplet state of the photoactivated sensitizer to ground state of oxygen. ${ }^{1,2}$ Singlet oxygen is a versatile synthetic reagent used for fine chemical synthesis to produce for instance pharmaceutical ingredients like artemisinin. ${ }^{3,4}$ Photooxidation is also of interest in wastewater treatment to promote insecticides and pesticides degradation. ${ }^{5,6}$ Under specific irradiation of a photosenstizer, the produced singlet oxygen has the ability to damage living tissue by oxidation of the cell wall, thus acting as oxidizing agent in photodynamic processes, including blood sterilization, photodynamic therapy $(\mathrm{PDT})^{7}$, photodynamic inactivation (PDI) (ie. light activated antimicrobial agent). ${ }^{8-12}$ In the present work, Rose Bengal (RB) was selected as nontoxic, commercially available photosensitizer. ${ }^{13}$ It exhibits an absorption band in the visible 
range $(540-560 \mathrm{~nm})$, a high singlet oxygen quantum yield $\left(\phi_{\Delta} \sim 0.6-0.75\right)$ in polar solvents and a sodium carboxylate function as platform for chemical reaction (Scheme $\mathrm{S} 1 \uparrow$ ). Immobilization of photosensitizers on solid substrates improves their handling, recyclability, stability and facilitates purification steps to remove photocatalyst from reactants in fine chemistry. ${ }^{14}$ Among the substrates for organic photosensitizers, polymers have known an increasing interest from their versatility in terms of mechanical properties and processability. Especially, polymer colloids can confer additional properties to the photoactive materials such as higher interfacial area, swelling ability, high stability in water or alcoholic medium, ON/OFF activity or filmforming properties. ${ }^{15-18}$ Waterborne latexes produced by emulsion polymerization are a class of polymer colloids directly synthesized in aqueous dispersed media. Emulsion polymerization ${ }^{19}$ is an inherently safe and environmentally friendly process that is widely implemented at industrial level to produce stable polymer colloids dispersed in a continuous water phase. Waterborne latex are used for a myriad of applications in paints and coatings, adhesives and sealants, paper, cement and concrete additives, floor polish, textiles, synthetic rubbers, and reinforced plastics but also in cosmetics, biomaterials and other high-tech areas. By producing one materials, waterborne latex grafted with photosensitizer could be handled as photoactive colloids or cast to produce films. Designing RB monomer should allow the synthesis of photosensitizer-based waterborne latex by conventional emulsion polymerization but one has to address the solubility of the powder form chromophore-based monomer either in water or in the monomer phase. Polymerization-induced self-assembly (PISA) ${ }^{20-24}$ is a versatile method to control the molar mass and location of the RB monomer units. For instance, PISA was implemented to control the design of fluorescently labeled particles either by post-modification with the fluorescent tag, ${ }^{25,26}$ or by copolymerization of dye-monomer with the core-forming monomer. ${ }^{27}$ Moreover, synthesis of waterborne latex by PISA gathers other advantages like suppression of labile molecular surfactant, direct synthesis of core-shell particles, control of 
macromolecular features of the core-forming polymer (molar mass, dispersity, branching...) or control of particle morphology (sphere, fiber, vesicle). ${ }^{20-24}$ The anchored hydrophilic shell of amphiphilic block copolymer particles synthesized by PISA also offer the opportunity to reinforce mechanical properties or water barrier properties of the final polymer films. ${ }^{28,29}$ Herein, poly(acrylic acid)- $b$-poly(alkyl acrylate) will be the polymeric system of choice in the present work to synthesize photosensitizer-based core-shell particles by emulsion PISA. Since the pioneering work on PISA involving oligo(acrylic acid) as the macromolecular chain transfer agent (macroCTA) and polymerization of $n$-butyl acrylate by emulsion polymerization, ${ }^{30}$ reversible addition-fragmentation chain transfer (RAFT) polymerization has been the main method to mediate emulsion PISA of alkyl acrylates by poly(acrylic acid) (PAA) macro(CTA). ${ }^{31-39}$ Recently, poly(2-( $N$-acryloyloxy)ethyl pyrrolidone) (PNAEP) was involved as nonionic stabilizer block in the synthesis of poly( $n$-butyl acrylate) latex by RAFT emulsion polymerization..$^{40}$ Nitroxide-mediated polymerization also produced polyacrylic diblock copolymer latex from PAA macroalkoxyamine. ${ }^{41,42}$

A versatile way to covalently anchor Rose Bengal photosensitizer is to synthesize a polymerizable monomer (MRB) that could be copolymerized with either acrylic acid (AA) to functionalize the particle shell or with alkyl acrylate for core functionalization (Scheme 1). For that purpose, two types of MRB were synthesized in the present work, vinyl benzyl Rose Bengal (VBRB, Scheme S1 $\dagger$ ) and ethyl acrylate Rose Bengal (EARB, Scheme S2 $\dagger$ ). Herein, the alkyl acrylate forming the particle core will range from $n$-butyl acrylate ( $n \mathrm{BA})$, ethyl acrylate (EA) or $n \mathrm{BA} / \mathrm{EA}$ mixture to tune the glass transition temperature from $-15^{\circ} \mathrm{C}$ to $-45^{\circ} \mathrm{C} .{ }^{43}$ This study will investigate whether the chemical nature of the polymer core or the location of the photosensitizer (shell versus core) might affect the interfacial ${ }^{1} \mathrm{O}_{2}$ production. In addition to be used as colloidal substrate in the present work, the design of poly(alkyl acrylate) particles offers a versatile strategy to use the supported photosensitizer as polymer films by simple casting of 
film-forming waterborne latex. ${ }^{18}$ It has been previously reported that the mechanical properties of polyacrylics vary according to the pendant chain length, ${ }^{44}$ and could be reinforced by the presence of H-bonding poly(acrylic acid) percolated nanophase..$^{29}$ Poly(acrylic acid) has been widely used in emulsion polymerization. Herein we will take advantage of the hydrophilic character of the neutralized PAA to transport the covalently bonded hydrophobic Rose Bengal photosensitizer moiety into the aqueous continuous phase of emulsion polymerization (Route 1 in Scheme 1). The main route of this work relies indeed in the introduction of the Rose Bengal photosensitizer in the outer shell via the design of $\mathrm{P}(\mathrm{AA}-\mathrm{co}-\mathrm{MRB})$ macromolecular chain transfer agent (macroCTA) (Route 1 in Scheme 1), but the copolymerization of MRB with the hydrophobic core-monomer will be also studied to a lesser extent (Route 2 in Scheme 1). Prior to implement emulsion PISA, it was relevant to investigate the control of AA RAFT polymerization and its copolymerization with MRB comonomers in three different solvents (1,4-dioxane, DMF, DMSO) to produce living macromolecular chain transfer agent. Since the early work of Chiefari et al., ${ }^{45}$ RAFT polymerization has been the most widely implemented reversible deactivation radical polymerization (RDRP) technique for AA polymerization carried out in solvents such as 1,4-dioxane, ${ }^{46-48}$ ethanol, ${ }^{47}$ 2-propanol, ${ }^{47} \mathrm{DMF}^{49}$ or water. ${ }^{50,51}$ DMSO is an interesting polar solvent for MRB solubilisation as alternative to more hazardous solvents such as 1,4-dioxane or DMF. To the best of our knowledge, RAFT polymerization of AA in DMSO has never been reported so far. The measurement of the quantum yield of singlet oxygen is a mean to accurately compare the photoactivity of each synthesized latex to produce singlet oxygen at the interface with water. 


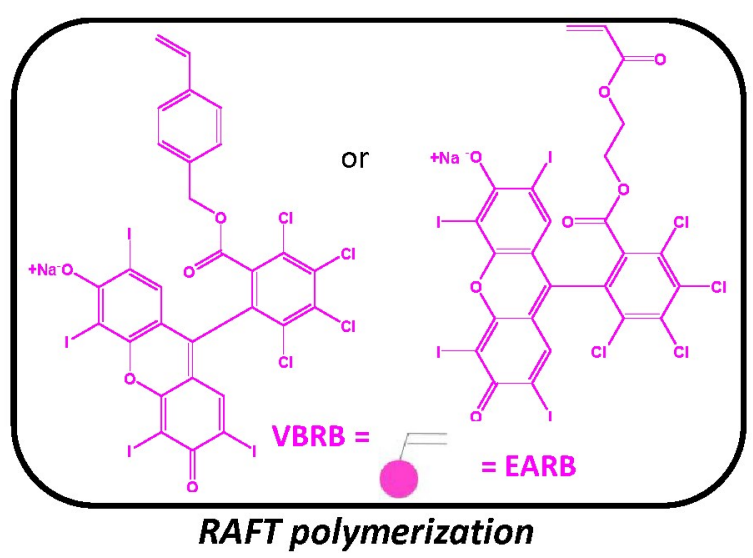

Acrylic acid (AA), ACPA, Solvent, $80^{\circ} \mathrm{C}$

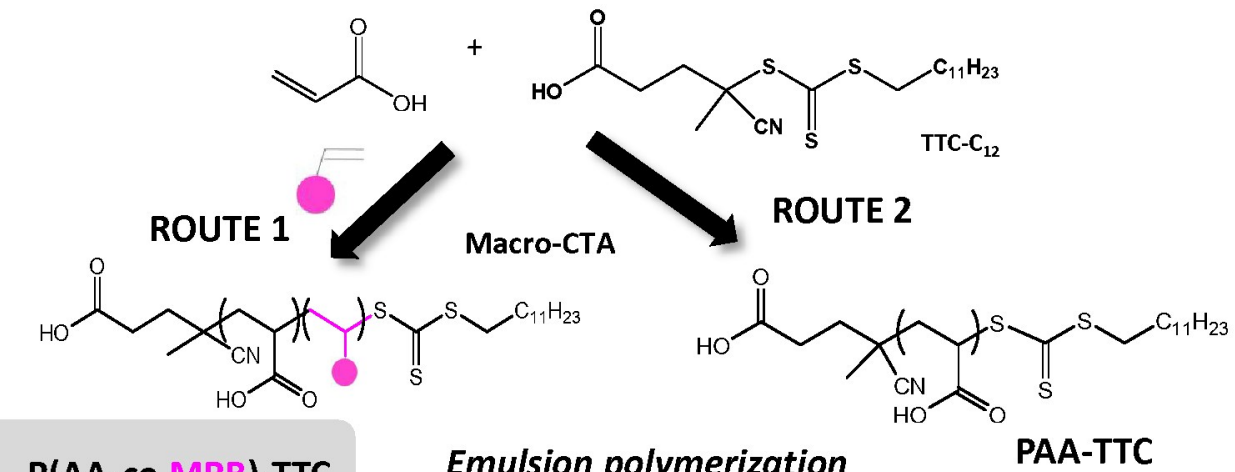

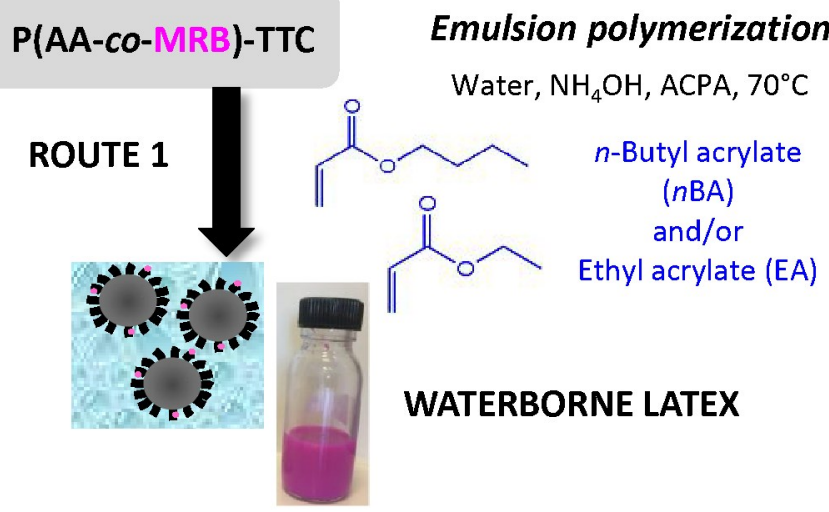

PAA-TTC

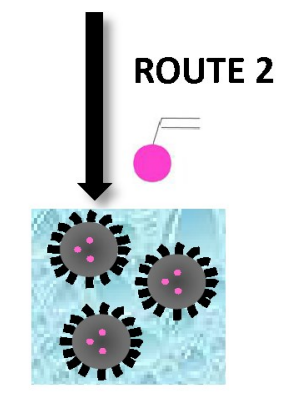

Scheme 1. Synthesis of P(AA-co-MRB)-TTC and PAA-TTC by RAFT polymerization used as reactive stabilizer for the synthesis of photosensitizer-based waterborne latex by emulsion PISA: Route 1 for RB in the shell and Route 2 for RB in the core. 


\section{Experimental section}

Materials. Acrylic acid (AA) (Sigma-Aldrich, 99\%), ethyl acrylate (EA) (Sigma-Aldrich, 99\%) and $n$-butyl acrylate ( $n \mathrm{BA})$ (Sigma-Aldrich, $>99 \%)$ were mixed with inhibitor removers (Sigma-Aldrich) for 30 min prior to being filtered and used for polymerization. Acryloyl chloride (Sigma-Aldrich, 97\%), 2-bromoethanol (Sigma-Aldrich, 95\%), triethylamine (TEA) (Sigma-Aldrich, 99.5\%), 4-vinylbenzyl chloride (VBC) (Sigma-Aldrich, 90\%), Rose Bengal (RB) (Sigma-Aldrich, 95\%), 1,3,5-trioxane (Sigma-Aldrich, $\geq 99 \%$ ), 4,4'-azobis(4cyanopentanoic acid) (ACPA) (Fluka, $\geq 98 \%)$, 4-Cyano-4-[(dodecylsulfanylthiocarbonyl) sulfanyl]pentanoic acid (TTC) (Sigma-Aldrich, 97\%), (trimethylsilyl)diazomethane solution (Sigma-Aldrich, 2.0 M in diethyl ether), hydrochloric acid (HCl) (Sigma-Aldrich, ACS reagent, 37\%), ammonium hydroxide $\left(\mathrm{NH}_{4} \mathrm{OH}\right.$ ) (Acros Organic, 28-30\% in water), anhydrous magnesium sulfate $\left(\mathrm{MgSO}_{4}\right)$ (Sigma-Aldrich, $\left.\geq 99.5 \%\right)$, sodium chloride $(\mathrm{NaCl})$ (SigmaAldrich, $\geq 99 \%$ ), furfuryl alcohol (Sigma-Aldrich, 98\%), 1,4-dioxane (Sigma-Aldrich, 99.8\%), dichloromethane (DCM) (VWR), diethyl ether (VWR), dimethylformamide (DMF) (SigmaAldrich), dimethyl sulfoxide (DMSO) (VWR), tetrahydrofuran (THF) (VWR), toluene (SigmaAldrich), deuterated chloroform $\left(\mathrm{CDCl}_{3}\right)$ (Sigma-Aldrich) were used as received. Deionized (DI) water was used for all emulsion polymerizations. Synthesis of vinyl benzyl Rose Bengal (VBRB) and ethyl acrylate Rose Bengal (EARB) are described in Supporting Information (Scheme $\mathrm{S} 1 \dagger$ and Scheme S2 †).

Synthesis of macromolecular chain transfer agent (PAA-TTC, P(AA-co-VBRB)-TTC, P(AA$\boldsymbol{c o - E A R B})-\boldsymbol{T T C})$. In a typical experiment (PAA-3), AA (2.355 g, 3.27.10-2 mol), TTC (188 mg, 4.67.10-4 mol), ACPA (13 mg, 4.67.10-5 mol), 1,3,5-trioxane (160 mg, 1.78.10-3 mol) and 1,4-dioxane $(9.725 \mathrm{~g}, 9.442 \mathrm{~mL})$ were introduced into a $50 \mathrm{~mL}$ round-bottom flask and stirred magnetically until complete dissolution (Scheme S3 †). The mixture was degassed by nitrogen 
bubbling during $20 \mathrm{~min}$. A sample was withdrawn under nitrogen at time $\mathrm{t}=0$. The roundbottom flask was placed into an oil bath previously heated to $80{ }^{\circ} \mathrm{C}$. Samples were withdrawn every 15 min until $1 \mathrm{~h}$ and then every $30 \mathrm{~min}$ until the reaction was stopped $(3 \mathrm{~h})$ by cooling down in an ice-water bath and by the introduction of oxygen in the mixture. The polymer was precipitated in diethyl ether and dried. A part of each sample was reacted with trimethylsilyldiazomethane to methylate the acid group of PAA and thus to allow size exclusion chromatography (SEC) analyses. The procedure used to synthesize P(AA-co-MRB)-TTC macromolecular RAFT agents was similar except that VBRB or EARB as MRB monomer was added in the initial mixture.

Monomer conversion $(x)$ was calculated from proton nuclear magnetic resonance $\left({ }^{1} \mathrm{H}\right.$ NMR) spectra using 1,3,5-trioxane as internal standard (Eq 1).

$$
x=\frac{\left(\frac{I_{1 \mathrm{HAA}} / 3}{I_{1 \mathrm{H} \text { triox }} / 6}\right)_{\mathrm{t}}}{\left(\frac{I_{1 \mathrm{HAA}} / 3}{I_{1 \mathrm{H} \text { triox }} / 6}\right)_{0}}
$$

$\mathrm{Eq} 1$

$\mathrm{I}_{1 \mathrm{H} \text {,triox }}$ corresponds to the integral of one proton of 1,3,5-trioxane $(5.1 \mathrm{ppm}, 6 \mathrm{H})$ used as internal standard and $\mathrm{I}_{1 \mathrm{H}, \mathrm{AA}}$ corresponds to the mean integrals of the AA vinylic protons $(3 \mathrm{H})$ at 5.9-6.3 ppm.

Synthesis of poly(alkyl acrylate)-based latexes by emulsion PISA. Emulsion polymerization of $n \mathrm{BA}$ is described in details but the procedures also apply to the emulsion polymerization of EA and the emulsion copolymerization of $n \mathrm{BA}$ and EA. Emulsion polymerizations were performed targeting $23 \mathrm{wt}-\%$ of solids content at $100 \%$ monomer conversion.

Synthesis of $P A A-b-P n B A$ and $P(A A-c o-M R B)-b-P n B A$ latexes. In a typical experiment (LBA12 in table $\mathrm{S} 7 \dagger)$, PAA-TTC macroCTA (546 mg, $\left.1.6 \times 10^{-4} \mathrm{~mol}\right)$ was dissolved in $42.5 \mathrm{~g}$ of 
deionized water. Then, the $\mathrm{pH}$ of the solution was adjusted to 5.4 by adding $1.4 \mathrm{~g}$ of $\mathrm{NH}_{4} \mathrm{OH}$ $28-30 \%$ in water. The equivalent of $8.5 \mathrm{mg}\left(3 \times 10^{-5} \mathrm{~mol}\right)$ of ACPA initiator was added via 1.1 $\mathrm{g}$ of a stock solution (38.6 mg of ACPA in $5.0 \mathrm{~g}$ of a stock solution of $1 \mathrm{~mL} \mathrm{NH}_{4} \mathrm{OH} 28-30 \%$ and $62.2 \mathrm{~g}$ deionized water), to target a molar ratio between macroCTA and initiator of 5.2. Finally, $n \mathrm{BA}(13.8 \mathrm{~g}, 0.11 \mathrm{~mol})$ was introduced and a biphasic system was formed. The emulsion was simultaneously stirred and purged with argon for $45 \mathrm{~min}$ in an ice bath to prevent monomer evaporation. The flask was introduced in an oil bath preheated to $70{ }^{\circ} \mathrm{C}$ and the reaction was stirred using a collapsible blade stirrer at $300 \mathrm{rpm}$. After $4 \mathrm{~h}$, the flask was dipped into an ice bath and opened to air. For the latexes synthesized from a macroCTA synthesized in DMSO or in DMF, the residual solvent contained in PAA was removed by dialysis of the latex for 2 days.

The monomer conversion for emulsion polymerization was determined by gravimetry. Around $1 \mathrm{~mL}$ of latex was withdrawn and dried overnight at room temperature in an aluminium cap. Conversions were calculated based on Eq 2 with $\tau_{P n B A, \exp }$ the experimental solids content calculated from Eq 3 and $\tau_{P n B A, t h e o}$ the theoretical solids content at $100 \%$ monomer conversion (Eq 4). Note that this calculation holds true for PAA- $b$-PEA latexes and RB-containing latexes.

$$
\begin{aligned}
& x_{\mathrm{nBA}}(\%)=\frac{\tau_{\mathrm{PnBA}, \text { exp }}}{\tau_{\mathrm{PnB}, \text { theo }}} \times 100 \mathrm{Eq} 2 \\
& \tau_{\mathrm{PBA}, \text { exp }}=\text { Dry extract }-\tau_{\text {salts }} \mathrm{Eq} 3 \\
& \tau_{\mathrm{PnBA}, \text { theo }}=m_{B A, 0} / m_{\text {latex }, 0} \mathrm{Eq} 4 \\
& \text { Dry extract }=\frac{m_{\text {dry sample }}}{m_{\text {latex }, 0}} \mathrm{Eq} 5 \\
& \tau_{\text {salts }}=\frac{m_{\text {initiator }}+m_{\text {macroCTA }}+m_{\mathrm{NH} 40 \mathrm{H}}}{m_{\text {latex }, 0}} \mathrm{Eq} 6
\end{aligned}
$$


Synthesis of $P A A-b-P(n B A-c o-M R B)$ latexes. In a typical experiment (LBA-VBRB3 in Table 3) the PAA-TTC macroCTA (PAA-8, $546 \mathrm{mg}, 1.6 \times 10^{-4} \mathrm{~mol}$ ) was dissolved in $42.5 \mathrm{~g}$ of deionized water. Then, the $\mathrm{pH}$ of the solution was adjusted to 5.4 by adding $1.6 \mathrm{~g}$ of $\mathrm{NH}_{4} \mathrm{OH} 28-30 \%$ in water. The equivalent of $8.7 \mathrm{mg}\left(3.1 .10^{-5} \mathrm{~mol}\right)$ of ACPA initiator was added via $0.9 \mathrm{~g}$ of a stock solution $\left(57.9 \mathrm{mg}\right.$ of ACPA in $5.9 \mathrm{~g}$ of a stock solution of $0.95 \mathrm{~g} \mathrm{NH}_{4} \mathrm{OH} 28-30 \%$ and $25 \mathrm{~g}$ deionized water), to target a molar ratio between macroCTA and initiator of 5.1. Finally, a mixture of VBRB $(7 \mathrm{mg})$ and $n \mathrm{BA}(13.8 \mathrm{~g}, 0.11 \mathrm{~mol})$ was introduced and a biphasic system was formed. The next steps are the same as for PAA- $b$-P $n$ BA synthesis.

Methylation PAA-b-poly(alkyl acrylate) block copolymer. Prior to perform size exclusion chromatography (SEC) analyses in THF, polymers were methylated to derivatize poly(acrylic acid) into poly(methyl acrylate). For that purpose, (trimethylsilyl)diazomethane (TMS) was used as efficient reactant. In a typical methylation, $100 \mathrm{mg}$ of latex ( $23 \mathrm{mg}$ of polymer) and 16 $\mathrm{mL}$ of THF were mixed. One drop of $1 \mathrm{M}$ hydrochloric acid $(\mathrm{HCl})$ solution was added to ensure that all the acid units were protonated. The solution of TMS was added dropwise in the mixture until the yellow coloration persists and there were no bubbles anymore (approximately 10 drops). The mixture has been stirred for 3 hours at room temperature then dried under the fume hood. The procedure was repeated one more time and the dried polymer was dissolved in dichloromethane to be extracted with DI water three times in order to remove the residual salts. After evaporation of dichloromethane and drying, copolymers were dissolved in THF to be analysed by SEC.

\section{Characterization methods.}

NMR spectra were recorded using a Bruker $400 \mathrm{MHz}$ spectrometer at $25^{\circ} \mathrm{C}$. The polymers were analysed by size exclusion chromatography (SEC) operating in THF, at $30{ }^{\circ} \mathrm{C}$ (flow rate: $\left.1 \mathrm{~mL} \cdot \mathrm{min}^{-1}\right)$. The SEC apparatus is equipped with a Viscotek-Malvern VE 1122 automatic injector, Styragel columns (HR 5E and 4E, $7.8 * 300 \mathrm{~mm}$, noted as set No. 1) working in series, 
a Wyatt Heleos II Multi Angle Laser Light Scattering detector (MALLS, 18 angles, $\lambda_{0}=664.4$ nm), a viscometer (Wyatt Viscostar II), a Viscotek-Malvern VE 3210 UV-visible detector and a refractive index (RI) detector Viscotek-Malvern VE 3580. A second set of SEC Shodex columns was used (KF 803L, KF 804L, KF 806L, $8 * 300 \mathrm{~mm}$, noted as set No. 2). Toluene was used as flow marker. Polymer samples were prepared at concentrations from 3 to 5 g. $\mathrm{L}^{-1}$. The number-average molar mass $\left(M_{\mathrm{n}}\right)$ and molar mass distribution (Đ) were obtained either from a calibration based on polystyrene standards or from MALLS (Astra software). See last part of Supporting Information for details on: $(i)$ the calculation of number-average molar mass $\left(M_{\mathrm{n}}\right)$ of PAA-based macroCTA calculated from the experimental molar mass of the methylated samples, (ii) the error between molar mass of polystyrene standards and poly(alkyl acrylate) based on Mark-Houwink parameters, (iii) refractive index increments $(\mathrm{dn} / \mathrm{dc})$ of polymers for MALLS analysis, (iv) equation for theoretical $M_{\mathrm{n}}$. UV-visible absorption spectra were recorded at $25^{\circ} \mathrm{C}$ with of PerkinElmer Lambda 850 spectrophotometer. The hydrodynamic diameter $D_{\mathrm{h}}$ was measured by dynamic light scattering (DLS) on a Nano-ZS (ZEN3600 Malvern) zetasizer, at a concentration of particle of $0.05 \mathrm{~g} . \mathrm{L}^{-1}$. A He-Ne laser $(4.0 \mathrm{~mW}$ power $)$ was used, operating at a wavelength of $633 \mathrm{~nm}$ at angle of $173^{\circ}$. The average number of latex particles per liter of latex $\left(N_{\mathrm{p}}\right)$ was calculated from the latex average hydrodynamic diameter (Eq 7). The polydispersity index (PDI) was measured with the cumulant model for monomodal distributions.

$N_{\mathrm{p}}\left(\right.$ particles.L $\left.\mathrm{L}_{\text {latex }}^{-1}\right)=\frac{6 \times \tau}{\pi \times D_{\mathrm{h}}^{3} \times \rho_{\text {polymer }}}$

$\operatorname{Eq} 7$

With $\tau$ the final solids content $\left(\mathrm{g} . \mathrm{L}^{-1}\right.$ latex $), \rho_{\text {polymer }}$ the density of the polymer $\left(\rho_{\mathrm{PnBA}}=1.03 \mathrm{~g} . \mathrm{cm}^{-3}\right.$ and $\left(\rho_{\mathrm{PEA}}=1.12 \mathrm{~g} \cdot \mathrm{cm}^{-3}\right)$. 
Differential scanning calorimetry (DSC) were carried out using the Q100 apparatus from TA Instruments. Analysis were conducted at a heating rate of $10^{\circ} \mathrm{C} / \mathrm{min}$, under nitrogen gas flow, from $-100{ }^{\circ} \mathrm{C}$ to $150{ }^{\circ} \mathrm{C}$. The measurements method included a first heating step from -100 to $150{ }^{\circ} \mathrm{C}$ at $10{ }^{\circ} \mathrm{C} \min ^{-1}$, a cooling step from $150{ }^{\circ} \mathrm{C}$ to $-100{ }^{\circ} \mathrm{C}$ at $10{ }^{\circ} \mathrm{C} \mathrm{min}-1$, and a second heating step from $-100{ }^{\circ} \mathrm{C}$ to $150{ }^{\circ} \mathrm{C}$ at $10{ }^{\circ} \mathrm{C} \mathrm{min}-1$. Glass transition temperatures $\left(T_{\mathrm{g}}\right)$ of the copolymer was measured during the second heating step.

The set-up for monitoring of singlet oxygen production is detailed in supporting Information.

\section{Results and discussion}

Synthesis of reactive stabilizer by RAFT polymerization: PAA-TTC and P(AA-co-MRB)-TTC macroCTA.

The high reactivity of acryclic acid in radical polymerization induces the occurrence of irreversible transfer reactions to solvent even for RDRP processes ${ }^{47,52}$ Such side reactions can be minimized for RAFT polymerization of AA by using 1,4-dioxane instead of protic alcoholic solvents. ${ }^{47}$ In the present work, more polar solvents such as DMF or DMSO were useful to solubilize Rose Bengal-based comonomer as MRB are less soluble in 1,4-dioxane and insoluble in water. Consequently, RAFT homopolymerization of AA mediated by TTC was first carried out in three different solvents $(1,4$-dioxane, DMF and DMSO, Table S1 $\dagger$ ) to compare the level of control prior to copolymerize AA with rose Bengal-based comonomer (Table 1, Table S3 †).

Lai et al. have successfully controlled the polymerization of AA in DMF by RAFT polymerization mediated by a trithiocarbonate chain transfer agent ${ }^{49}$ but to the best of our knowledge, RAFT polymerization of AA in DMSO has never been reported so far. While DMF is a carcinogenic solvent, DMSO is a non-hazardous solvent widely used in industry. Herein, AA was successfully polymerized at $80^{\circ} \mathrm{C}$ by RAFT polymerization mediated by 4-cyano-4[(dodecylsulfanylthiocarbonyl)sulfanyl]pentanoic acid (trithiocarbonate chain transfer agent, 
TTC) (Scheme S3 in ESI) using 4,4'-azobis(4-cyanopentanoic acid) (ACPA) initiator up to high conversions (88-93\%) in the three different solvents (1,4-dioxane, DMSO or DMF) (Table S1 $\dagger$ ). Kinetics of AA RAFT polymerization in 1,4-dioxane and in DMF perfectly superimposed with a linear increase of logarithmic conversion versus time up to $80 \%$ of conversion, indicating a constant concentration of propagating radicals (Fig. S2 $\uparrow$ and Fig. 1). The good reproducibility of AA kinetics is reported in Fig. S1 †. At higher conversions, the loss of linearity suggests a slight occurrence of irreversible termination reactions or transfer to polymer producing less reactive radicals. Interestingly, DMSO induced a 2.7-fold increase of AA polymerization rate while maintaining a constant concentration of radicals up to $80 \%$ of conversion (Fig. S2 † and Fig. 1). Such discrepancies between the polymerization rates can be due to intrinsic characteristics of the different solvents. The polarity of DMSO, expressed either by the normalized polarity $\left(\mathrm{E}_{\mathrm{T}}^{\mathrm{N}}\right)$ values, ${ }^{53}$ or by the dipolarity/polarizability parameters ${ }^{54}$, is higher than for 1,4-dioxane and DMF (Table S2 $\dagger$ ). Previous studies reported an effect of the solvent polarity on radical polymerization process. For instance, Beuermann et al. ${ }^{55}$ showed an increase of the propagation rate coefficient of methyl methacrylate with the solvent dipolarity/polarizability of ionic liquids or polar organic solvents like DMSO. Horn et al. ${ }^{56}$ also evidenced the relationship between the dipolarity/polarizability of the solvent and the activation rate constant in atom transfer radical polymerization (ATRP). In the presence work, the increase of AA polymerization rate with the solvent polarity may arise from a better solvatation of the polar polymeric radicals, thus a higher reactivity. The increase of polymerization rate in DMSO is particularly relevant for the implementation of RAFT copolymerization of AA with Rose Bengal-based comonomer (MRB) (Fig. 1, Table 1, Table S3 †). Indeed, 0.2-0.5 mol-\% of VBRB induces a strong retardation of AA RAFT polymerization in 1,4-dioxane (to a lesser extent for EARB) which is fully overcome in DMSO and observed at intermediate level (40\% of slope decrease) in DMF (Fig. 1). 


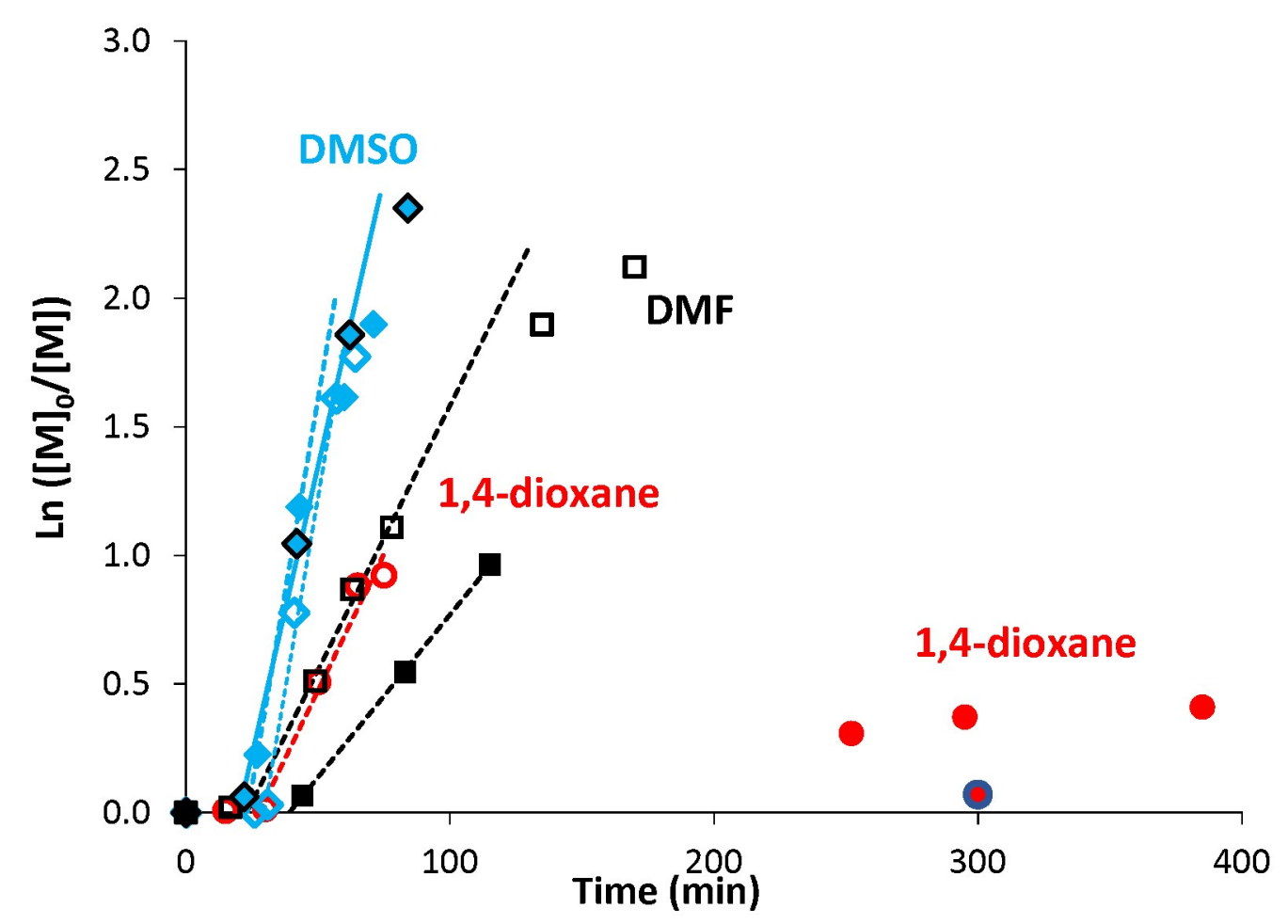

Fig. 1. Comparison of semilogarithmic conversion of AA versus time for the RAFT polymerization carried out at $\mathrm{T}=80^{\circ} \mathrm{C}$ in different solvents: diamonds for DMSO, squares for DMF and circles for 1,4-dioxane. Empty signals for 0 mol- $\%$ of MRB $(\diamond$ PAA-8, $\square$ PAA-10, O PAA-7), and plain symbols for copolymerization of AA with $0.25 \mathrm{~mol} \%$ of EARB $(\diamond$ PAAEARB 8 ), $0.25 \mathrm{~mol} \%$ of VBRB ( $\diamond$ PAA-VBRB6, in dark), $0.25 \mathrm{~mol} \%$ of VBRB (ם PAAVBRB7), $0.21 \mathrm{~mol} \%$ of EARB (PAA-EARB6), $0.50 \mathrm{~mol} \%$ of VBRB (PAA-VBRB3). See Table 1, Table S1† and Table S3† for the polymer description.

It should be noticed that minor retardation was observed for polymerization carried out in 1,4dioxane in the presence of 0.5 mol- $\%$ of free $\mathrm{RB}$ compared to inhibition of polymerization for copolymerization of 0.5 mol- $\%$ of VBRB (Fig. S6 $\dagger$ ). Also, RAFT copolymerization of AA and MRB carried out in dark exhibited comparable polymerization rate to copolymerization at ambient light in both DMSO (Fig. 1) and 1,4-dioxane (Fig. S6 †). Increasing molar fraction of MRB co-monomer induced a decrease of the polymerization rate (Fig. 1, Fig. S6 $\uparrow$, Fig. S7 †). In 1,4-dioxane, the retardation of AA copolymerization is particularly obvious for molar ratio of MRB comonomer over ACPA initiator above unity (Table 1, Table S3 $\dagger$ ). The hypothesis of 
light-activated side reactions inducing retardation of the RAFT AA/MRB copolymerization is inconsistent with the literature. Indeed, while xanthene dyes (including RB) are able to act as initiating system producing radicals from the trithiocarbonate chain transfer agent by photoinduced electron/energy transfer (PET) under specific LED-driven light irradiation, xanthene dyes are inactive in radical production under simple ambient visible light. ${ }^{57}$ As no specific irradiation was used for the RAFT AA/MRB copolymerization reported in the present study, it is unlikely that side PET-RAFT polymerization process occurs. Thus, the retardation of polymerization is rather due to the chemical structure of MRB rather than MRB-induced side photochemical process. This is confirmed by a more pronounced polymerization retardation induced by vinyl benzyl Rose Bengal compared to ethyl acrylate Rose Bengal in 1,4-dioxane (Fig. 1 and Fig. S6 $\dagger)$. A fraction of 0.1 mol-\% $(\sim 1.5$ wt- $\%)$ of EARB or VBRB induced a decrease of the apparent rate constant (ie slope of $\ln \left([\mathrm{M}]_{0} /[\mathrm{M}]\right)=\mathrm{f}(\mathrm{t})$ ) respectively of $25 \%$ or $45 \%$ compared to AA RAFT polymerization (Fig. S6 $\dagger$ ). A quasi-inhibition of the polymerization is observed for 6 hours with 0.5 mol- $\%$ of VBRB $(6.9 \mathrm{wt}-\%)$ and polymerization kinetics in the presence of 0.1 mol- $\%$ of VBRB are typical of slow initiation (PAA-VBRB3 in Fig. S6 $\dagger$ ). This inhibition is not ascribed to VBRB solubility issue as the limit concentration of solubility of VBRB measured in 1,4-Dioxane and DMSO (see Table S12 $\dagger$ ) is far beyond VBRB concentration in AA RAFT copolymerization $\left(0.3 \times 10^{-2}\right.$ mol.L ${ }^{-1}<[\mathrm{VBRB}]<1.7 \times 10^{-2} \mathrm{~mol} . \mathrm{L}^{-}$ $\left.{ }^{1}\right)$. It has been previously reported that the protons at the benzylic position are rather labile and prone to radical abstraction or other transfer reactions. ${ }^{58-61}$ While these previous studies showed an impact on macromolecular features like a broader molar mass distribution, they did not show such inhibition of polymerization kinetics. The RB pendant group has probably an additional effect on the radical produced after transfer reaction. The higher polymerization rate of AA/MRB RAFT copolymerization in polar DMSO might kinetically counterbalance such side reactions as no retardation is observed by adding VBRB or EARB (Fig. 1). Increasing the 
fraction of both Rose Bengal-based comonomer did not affect the length of inhibition period of RAFT polymerization but induced an earlier deviation from linearity characteristic of a decrease of radical concentration (Fig. S7 $\dagger$ ). As intermediate conclusion, high monomer conversions are reached in DMSO for the successful synthesis of P(AA-co-MRB)-TTC statistical copolymer by RAFT polymerization mediated by TTC.

The linear increase of experimental $M_{\mathrm{n}}$ versus conversion, close to theoretical $M_{\mathrm{n}}$ (Fig. S3 $\dagger$ ) supports a good level of control of the RAFT homopolymerization of AA mediated by TTC in DMSO, 1,4-dioxane and DMF. The slight deviation of $M_{n}$ versus linearity observed above 75 $\%$ of conversion (Fig. S3 $\dagger$ ) can be ascribed to transfer reactions to solvent, as already reported by Loiseau et al. ${ }^{47}$ and/or inaccuracy in the SEC values due to long chain branching (LCB). Indeed, radical polymerization of AA is prone to transfer reactions to polymer leading to branching. ${ }^{62}$ In case of long-chain branching (LCB), the variation of chains hydrodynamic volume may affect the determination of $M_{\mathrm{n}}$. Increase of $M_{\mathrm{n}}$ versus conversion is still observed for RAFT copolymerization of AA with MRB in DMSO (Fig. 2).

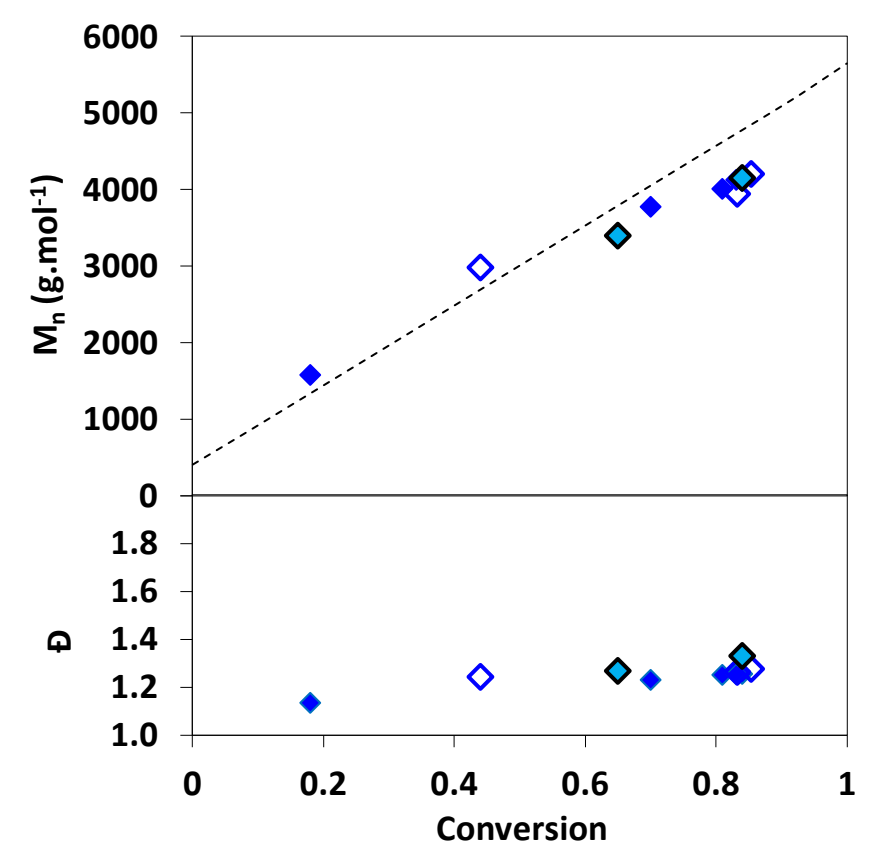


Fig. 2. Evolution of the number-average molar mass and the dispersity versus monomer conversion for the RAFT (co)polymerization of AA in DMSO with $0 \mathrm{~mol} \%$ of MRB $(\triangle \mathrm{PAA}-$ $8), 0.36 \mathrm{~mol} \%$ of EARB $(\diamond$ PAA-EARB4) or $0.25 \mathrm{~mol} \%$ of VBRB $(\diamond$ PAA-VBRB 6$)$. Dotted line: theoretical number-average molar mass. $\mathrm{M}_{\mathrm{n}}$ of PAA-TTC recalculated from $\mathrm{M}_{\mathrm{n}}$ of PMATTC (Eq S7 †) determined by SEC/polystyrene calibration in THF.

The series of PAA-TTC and P(AA-co-MRB)-TTC synthesized in the three different solvents exhibited monomodal SEC chromatograms with dispersity values below 1.4 at final conversion (Table 1, Fig. S4, Fig. S8, Table S1, Table S3 $\dagger$ ). The shift of the narrow SEC chromatograms of PAA-TTC towards lower elution volumes throughout the polymerization confirmed the control of polymerization in the different solvents (Fig. S5 $†$ ).

Characterization of chain end fidelity of PAA-TTC and P(AA-co-MRB)-TTC macroCTA.

Among the criteria of a controlled radical polymerization, more importantly for the synthesis of latex particles by PISA is to assess the retention of the reactive trithiocarbonate end group of both PAA-TTC and P(AA-co-MRB)-TTC polymers further used as reactive stabilizer in emulsion polymerization (Scheme 1). For that purpose, the end group fidelity of the macromolecular chain transfer agents was first analyzed by UV-visible spectroscopy in order to calculate the average number of moles of TTC end group per number of moles of PAA chain $\left(N_{\mathrm{TTC} / \mathrm{chain}}\right.$, Fig. S11 $\uparrow$, Fig. S12 $\left.\uparrow\right)$. The TTC function exhibits a maximum absorption band, assigned to a $\pi-\pi *$ transition, at $307 \mathrm{~nm}$ in ethanol (Fig. S9 $\dagger$ ). The average value of $N_{\mathrm{TTC} / \text { chain }}$ for PAA-TTC is $1.0 \pm 0.2$ (standard deviation based on 8 samples), $1.2 \pm 0.1$ (based on 2 samples) and 0.8 (based on 1 sample) for polymerization carried out respectively in 1,4dioxane, DMSO and DMF (Table S4 †). The good level of chain end fidelity is also maintained for copolymerization of AA with either $\mathrm{EARB}$ or VBRB as the average value of $N_{\mathrm{TTC} / \mathrm{chain}}$ is $1.0 \pm 0.4$ (standard deviation based on 8 samples), $1.3 \pm 0.2$ (based on 5 samples) and $1.2 \pm 0.2$ (based on 2 samples) for polymerization carried out in respectively 1,4-dioxane, DMSO and 
DMF (Fig. S11 and Table S4 $\dagger$ ). The TTC chain-end of the macroCTA was also evidenced by ${ }^{1} \mathrm{H}$ NMR with the presence of additional peaks corresponding to the carbon chain of the $\mathrm{Z}$ stabilizing fragment of the initial TTC chain transfer agent (Fig. S10 $\dagger$ ). A similar trend for the degree of functionalization was observed (Fig. S12 †). So, considering the standard deviation $( \pm 0.2$ or \pm 0.4$)$ for each technique and the relative error between $N_{\mathrm{TTC} / \text { chain }}$ calculated by UVvisible spectroscopy and ${ }^{1} \mathrm{H}$ NMR (see Table S4 and Fig. S11 $\dagger$ ) it can be concluded that the solvent used for RAFT polymerization does not compromise the chain end retention. Both PAA-TTC and P(AA-co-MRB)-TTC could be considered as reactive macromolecular chain transfer agent for emulsion PISA as the average values of $N_{\mathrm{TTC} / \mathrm{chain}}$ close to 1 depicts a high degree of the trithiocarbonate chain end functionalization (see Fig. S11 †, Table S4 $\dagger$ ). Monitoring the individual conversion of MRB and AA by ${ }^{1} \mathrm{H}$ NMR to assess the relative reactivity of both monomers is not possible at such low level of molar concentration $(<0.5$ mol$\%,<7$ wt- $\%$ based on AA) to prove the effective copolymerization. The overlay of the UVvisible $(570 \mathrm{~nm})$ and the refractometer traces of SEC chromatograms observed for P(AA-coEARB $_{0.21 \%}$ )-TTC copolymer indicates the presence of EARB monomer in the copolymer (Fig. $\mathrm{S} 13 \dagger)$. The covalent bond between RB moiety and polymer was also confirmed by thin layer chromatography (TLC) for $\mathrm{P}\left(\mathrm{AA}-\mathrm{co}-\mathrm{EARB}_{0.21 \%}\right)$-TTC and $\mathrm{P}\left(\mathrm{AA}-\mathrm{co}-\mathrm{EARB}_{0.4 \%}\right)-\mathrm{TTC}$ copolymers. While pink spot characteristic of free EARB dye moved up the TLC plate with the eluent (Fig. S14 left, spot (1) $\dagger$ ), the main fraction of P(AA-co-EARB $\left.{ }_{0.21 \%}\right)$-TTC and P(AA-coEARB $_{0.4 \%}$ )-TTC copolymers (PAA-EARB6 and PAA-EARB7) was retained by the stationary phase, confirming the successful copolymerization of AA with EARB. For sake of comparison, when a mixture of PAA-TTC and EARB was cast onto the TLC plate and subjected to the eluent migration, EARB moved up the plate, indicating that the polymer did not retained the RB-based co-monomer (spot (3) in Fig. S14 left and spot (4) in Fig. S14 right). Due to the low molar ratio of MRB, no quantifiable characteristic signal of MRB was observed by ${ }^{1} \mathrm{H}$ NMR 
analysis of the precipitated $\mathrm{P}(\mathrm{AA}-\mathrm{co}-\mathrm{MRB})$. On the other hand, such composition can be evaluated by UV-visible spectroscopy since the MRB moiety in the copolymer exhibits a distinct absorbance band at $\lambda_{\max }=568-569 \mathrm{~nm}$ in ethanol (see Fig. S9 $\dagger$ ). Detailed calculations on theoretical and experimental MRB loading are provided in Supporting Information. The results are gathered in Table $\mathrm{S} 5 \dagger$ to show an experimental MRB weight loading in the precipitated copolymer ranging from 5 to $33 \mu$ mol.g polymer $^{-1}$. The composition of copolymer is indeed tuned by the initial molar fraction of MRB as a linear increase of experimental MRB loading versus theoretical one is observed with a slope of 0.9 (Fig. S15 †).

Emulsion PISA for the synthesis of waterborne latex by route 1 (Scheme 1).

In the first part of this study, we highlighted by UV-visible spectroscopy and ${ }^{1} \mathrm{H}$ NMR that the chain end fidelity of PAA-based polymers was maintained at a good level whatever the solvent used for RAFT polymerization (1,4-dioxane, DMSO, DMF) but also in the presence of the photoactive MRB comonomer. In the present work, the main route chosen to synthesize the photoactive latexes is based on emulsion PISA mediated by P(AA-co-MRB)-TTC macroCTA in its neutralized form (Route 1 in Scheme 1). In order to confirm the efficacy of poly(ammonium acrylate) $\left(\mathrm{PA}^{-} \mathrm{NH}_{4}^{+}\right)$to act as reactive stabilizer for in-situ synthesis of amphiphilic block copolymers whatever the solvent used for PAA-TTC synthesis (1,4-dioxane, DMSO, DMF), a series of RB-free $\mathrm{P} n \mathrm{BA}, \mathrm{P}(n \mathrm{BA}-c o-\mathrm{EA})$ and PEA latexes were first synthesized by emulsion PISA (Table S6 and Table S7). Note that the synthesis of PAA- $b$ PnBA block copolymer latex has already been reported by Chenal et al. ${ }^{48,63}$ from PAA synthesized by RAFT in 1,4-dioxane, but neither EA homopolymerization nor $n \mathrm{BA} / \mathrm{EA}$ copolymerization by emulsion PISA has been reported so far. In addition to the interest of tuning the mechanical properties of polyacrylics via the pendant chain length, ${ }^{44}$ EA monomer is also interesting to be compared to $n \mathrm{BA}$ in emulsion PISA to investigate the impact of both 
the limit of monomer solubility in water and the polymerization rate constant on emulsion kinetics. While the saturation concentration in water intuitively increases by decreasing the number of carbons in the ester side-chain of $n$-alkyl acrylates, ${ }^{19}$ the propagation rate coefficient $\left(k_{\mathrm{p}}\right)$ more slightly decreases for shorter length of the alkyl side chain (Fig. S16 $\left.\dagger\right)$. It can be concluded from Fig. 3 that kinetics of emulsion PISA mediated by the neutralized PAA-TTC or $\mathrm{P}\left(\mathrm{AA}-\mathrm{co}-\mathrm{EARB}_{0.1 \%}\right)$-TTC are mainly affected by the monomer saturation concentration in water as the length of the inhibition period is three times shorten for EA compared to BA.

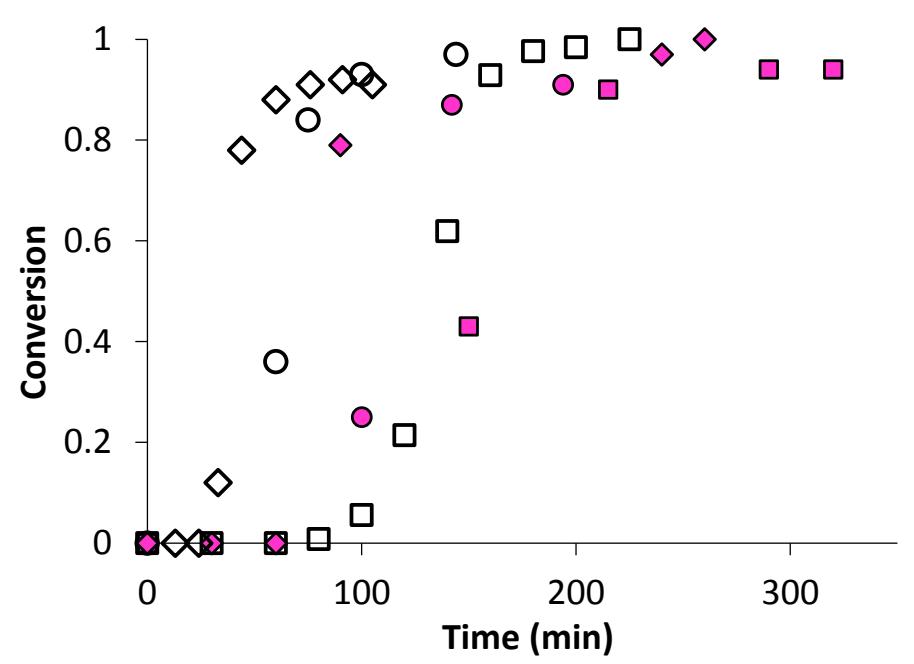

Fig. 3. Monomer conversion versus time for emulsion PISA: comparison of monomer $(\diamond)$ EA (LEA-14), (O) $n \mathrm{BA}_{70 \%} / \mathrm{EA}_{30 \%}$ (LBAEA-13), ( $\square$ ) $n \mathrm{BA}(L \mathrm{BA}-8)$ from either PAA-TTC (empty symbols) or P(AA-co-EARB ${ }_{0.1 \%}$-TTC) (pink plain symbols) (LEA-EARB1, LBAEA-EARB1, $L B A-E A R B 1)$. See Table 2 and Table $\mathrm{S} 6 \dagger$.

This inhibition period is characteristic of the nucleation period of emulsion polymerization. It corresponds to the creation of the initial particles (ie nuclei), so for PISA process to the time of polymerization to reach a sufficient length of hydrophobic second block inducing block copolymer self-assembly. The apparent rate of propagation, estimated from the slope of the linear part after the nucleation period, is also 4 times higher for EA polymerization. The $\mathrm{EA} / n \mathrm{BA}$ copolymerization exhibit intermediate trend. Analogously to AA/EARB copolymerization carried out in the less polar 1,4-dioxane solvent, emulsion polymerization of 
$n$-alkyl acrylates faced slight retardation in the presence of 0.1 mol- $\%$ EARB in the initial macroCTA (Fig. 3). It can be mentioned that all waterborne latexes of the present work are synthesized with final monomer conversion above $90 \%$ within 7 hours of polymerization (see Table 2, Table 3, Table S7 †, Fig. S17 †, Fig. S18 †). 
Table 2. Experimental conditions and results for the emulsion polymerizations of $n \mathrm{BA}$ and/or EA mediated by P(AA-co-MRB)-TTC from Table 1. Polymerization carried out at $70{ }^{\circ} \mathrm{C}$ with $23 \mathrm{wt}-\%$ of targeted solids content at $100 \%$ conversion and initial $\mathrm{pH}=5.4($ adjusted with $\mathrm{NH} 4 \mathrm{OH})$. $[\mathrm{ACPA}]_{0}=7.2$ to $8.8 \times 10^{-4}$ mol. $\mathrm{L}_{\mathrm{H} 20^{-1}}$.

\begin{tabular}{|c|c|c|c|c|c|c|c|c|c|c|c|c|}
\hline $\begin{array}{l}\text { Macro- } \\
\text { CTA }\end{array}$ & $\begin{array}{c}\text { Latex } \\
\text { expt }\end{array}$ & Polymer & $\begin{array}{c}\omega^{\mathrm{a}} \\
(\mathbf{w t}-\%)\end{array}$ & $\begin{array}{c}{\left[\mathrm{M}_{0}\right.} \\
\left(\mathrm{mol}_{\mathbf{0}} \mathrm{L}_{\mathrm{H20}}{ }^{-1}\right)\end{array}$ & $\begin{array}{c}{[\text { MacroCTA }]_{0}} \\
{\left[10^{-3} \text { mol.L }_{\left.\mathbf{H}^{-1} 0^{-1}\right]}\right.}\end{array}$ & $\frac{[\text { MacroCTA }]_{0}}{[\mathbf{A C P A}]_{0}}$ & $\begin{array}{c}\text { Conv } \\
(\%)\end{array}$ & $\begin{array}{c}M_{n, t h}{ }^{\mathrm{c}} \\
\left(\mathrm{kg} \cdot \mathrm{mol}^{-1}\right)\end{array}$ & $\begin{array}{c}M_{n, P S}{ }^{\mathrm{d}} \\
\left(\mathrm{kg} \mathrm{mol}^{-1}\right) \\
\text { (Đ) }\end{array}$ & $\begin{array}{c}M_{n, M A L L S} \\
\mathrm{e} \\
\left(\mathrm{kg} \cdot \mathrm{mol}^{-1}\right) \\
\text { (Đ) }\end{array}$ & $\begin{array}{c}D_{h} \text { f } \\
(\mathbf{n m}) \\
(\mathrm{PDI})\end{array}$ & $\begin{array}{c}N_{p} \mathrm{~g} \\
\left(10^{17} \mathrm{~L}_{\text {latex }}{ }^{-1}\right)\end{array}$ \\
\hline $\begin{array}{l}\text { PAA- } \\
\text { EARB2 }\end{array}$ & $\begin{array}{l}\text { LBA- } \\
\text { EARB1 }\end{array}$ & $\begin{array}{c}\mathrm{P}\left(\mathrm{AA}-c o-\mathrm{EARB}_{0.1 \%}\right)- \\
b-\mathrm{P} n \mathrm{BA}\end{array}$ & 3.4 & 2.5 & 2.3 & 3.1 & 94 & 139 & $\begin{array}{l}136^{\mathrm{i}} \\
(5.3)\end{array}$ & $\begin{array}{l}426^{\mathrm{i}} \\
(2.1)\end{array}$ & $\begin{array}{c}76 \\
(0.08)\end{array}$ & 9.2 \\
\hline $\begin{array}{l}\text { PAA- } \\
\text { EARB3 }\end{array}$ & $\begin{array}{l}L B A- \\
\text { EARB2 }\end{array}$ & $\begin{array}{c}\mathrm{P}\left(\mathrm{AA}-c o-\mathrm{EARB}_{0.1 \%}\right)- \\
b-\mathrm{P} n \mathrm{BA}\end{array}$ & 6.2 & 2.5 & 3.6 & 5.0 & 93 & 89 & $\begin{array}{l}100^{\mathrm{i}} \\
(7.2)\end{array}$ & $\begin{array}{l}373^{\mathrm{i}} \\
(2.3)\end{array}$ & $\begin{array}{c}80 \\
(0.05)\end{array}$ & 7.9 \\
\hline $\begin{array}{l}\text { PAA- } \\
\text { EARB4 }\end{array}$ & $\begin{array}{l}\text { LBA- } \\
\text { EARB3 }\end{array}$ & $\begin{array}{c}\mathrm{P}(\mathrm{AA}-c o- \\
\left.\text { EARB }_{0.36 \%}\right)-b-\mathrm{P} n \mathrm{BA}\end{array}$ & 5.7 & 2.6 & 4.2 & 5.6 & 93 & 78 & $\begin{array}{l}202 \text { i } \\
(5.7)\end{array}$ & $\begin{array}{l}203^{\mathrm{i}} \\
(1.8)\end{array}$ & $\begin{array}{c}83 \\
(0.06)\end{array}$ & 7.0 \\
\hline $\begin{array}{l}\text { PAA- } \\
\text { VBRB1 }\end{array}$ & $\begin{array}{c}L B A- \\
\text { VBRB1 }\end{array}$ & $\begin{array}{c}\mathrm{P}\left(\mathrm{AA}-c o-\mathrm{VBRB}_{0.1 \%}\right)- \\
b-\mathrm{P} n \mathrm{BA}\end{array}$ & 4.3 & 2.6 & 3.6 & 5.0 & 98 & 93 & $\begin{array}{l}135 \\
(3.9)\end{array}$ & $\begin{array}{l}343^{\mathrm{h}} \\
(1.6)\end{array}$ & $\begin{array}{l}96^{\mathrm{h}} \\
(0.04)\end{array}$ & 4.8 \\
\hline $\begin{array}{l}\text { PAA- } \\
\text { VBRB2 }\end{array}$ & $\begin{array}{c}L B A- \\
\text { VBRB2 }\end{array}$ & $\begin{array}{c}\mathrm{P}(\mathrm{AA}-c o- \\
\left.\mathrm{VBRB}_{0.25 \%}\right)-b-\mathrm{P} n \mathrm{BA}\end{array}$ & 5.6 & 2.6 & 3.7 & 4.8 & 98 & 93 & $\begin{array}{l}88^{i} \\
(3.2)\end{array}$ & $\begin{array}{l}237^{i} \\
(1.5)\end{array}$ & $\begin{array}{c}140 \\
(0.17)\end{array}$ & 1.5 \\
\hline $\begin{array}{l}\text { PAA- } \\
\text { EARB2 }\end{array}$ & $\begin{array}{l}\text { LBAEA } \\
\text {-EARB1 }\end{array}$ & $\begin{array}{c}\mathrm{P}\left(\mathrm{AA}-c o-\mathrm{EARB}_{0.1 \%}\right)- \\
b-\mathrm{P}\left(n \mathrm{BA}_{70 \%} / \mathrm{EA}_{30 \%}\right)\end{array}$ & 3.8 & 2.7 & 1.8 & 3.2 & 91 & 125 & $\begin{array}{l}141^{\mathrm{i}} \\
(4.3)\end{array}$ & $\begin{array}{l}322 \text { i } \\
(2.0)\end{array}$ & $\begin{array}{c}74 \\
(0.06)\end{array}$ & 9.3 \\
\hline $\begin{array}{l}\text { PAA- } \\
\text { EARB1 }\end{array}$ & $\begin{array}{l}\text { LEA- } \\
\text { EARB1 }\end{array}$ & $\begin{array}{c}\mathrm{P}\left(\mathrm{AA}-c o-\mathrm{EARB}_{0.1 \%}\right)- \\
b-\mathrm{PEA}\end{array}$ & 6.2 & 3.0 & 4.7 & 5.3 & 100 & 69 & $\begin{array}{l}136^{\mathrm{i}} \\
(3.2)\end{array}$ & $\begin{array}{l}243^{\mathrm{i}} \\
(1.8)\end{array}$ & $\begin{array}{c}95 \\
(0.04)\end{array}$ & 4.2 \\
\hline
\end{tabular}

${ }^{\mathrm{a}}$ Final $\mathrm{P}(\mathrm{AA}-c o-\mathrm{MRB})-\mathrm{TTC}$ weight fraction $=m_{0}(\mathrm{P}(\mathrm{AA}-c o-\mathrm{MRB})-\mathrm{TTC}) /\left[m_{0}(\mathrm{P}(\mathrm{AA}-c o-\mathrm{MRB})-\mathrm{TTC})+m_{0}(n \mathrm{BA}\right.$ or EA $) \times$ conversion $] .{ }^{\mathrm{b}}$ Conversion calculated by gravimetry (Eq 2). ${ }^{\mathrm{c}}$ Theoretical $M_{n}$ of block copolymers calculated from Eq S15† and Eq S16 $\dagger$. ${ }^{\text {dee }}$ Experimental $M_{\mathrm{n}}$ of block copolymers recalculated from $M_{\mathrm{n}}$ of methylated block copolymers determined by SEC in THF (Eq S7 $\dagger$ ). ${ }^{\mathrm{d}}$ Values obtained from a refractometer detector using PS calibration. ${ }^{\mathrm{e}}$ Values obtained from a MALLS detector. ${ }^{\mathrm{f}}$ Hydrodynamic diameter of particles measured by DLS. ${ }^{\mathrm{g}}$ Average number of particles determined from $D_{\mathrm{h}}(\mathrm{Eq} 7) .{ }^{\mathrm{h}}$ Analysed with set No.1 of SEC columns. ${ }^{\mathrm{i}}$ Analysed with set No.2 of SEC columns (see experimental part). 
The overlay of emulsion PISA kinetics whatever the solvent used for the synthesis of the PAAbased stabilizers (Fig. S17 $\uparrow$, Fig. S18 $\dagger$ ) is in accordance with the high level of chain end functionalization of the initial macroCTA. Moreover, the obvious shift of SEC chromatogram after emulsion polymerization confirms the chain end fidelity of macroCTA allowing a successful synthesis of block copolymers (Fig. 4, Fig. S19† and Fig. S20 †). Chain extension is observed from PAA-TTC synthesized in either in DMSO (Fig. 4a) or 1,4-dioxane (Fig. S20 $\dagger)$. Note that chain extension is also effective from the photoactive $\mathrm{P}\left(\mathrm{AA}-\mathrm{co}-\mathrm{EARB}_{0.36 \%}\right)$-TTC in the absence of residual macroCTA (Fig. 4b).
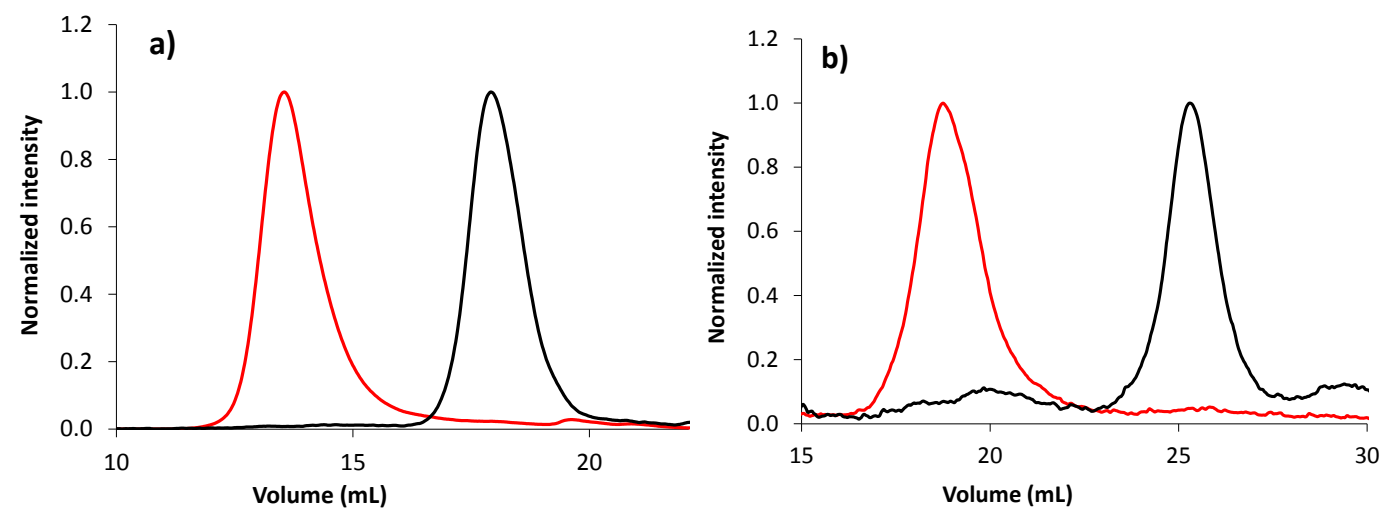

Fig. 4. Normalized SEC chromatograms of (a) PAA- $b-\mathrm{P} n \mathrm{BA}$ block copolymer ( $L \mathrm{BA}-11$ in Table S7 $\uparrow$, set No.1 of SEC columns) and (b) P(AA-co-EARB $\left.{ }_{0.36}\right)-b$-P $n$ BA block copolymer (LBA-EARB3 in Table 2, set No.2 of SEC columns) synthesized by emulsion PISA. The black traces correspond to the first PAA-based macroCTA and the red traces to the diblock copolymer. Light scattering traces at $\theta=90^{\circ}$ are depicted, see the corresponding RI traces in Fig. S19 †.

As depicted in Table 2 and Table S7†, the number-average molar masses of the diblock copolymer measured by SEC from a PS calibration (named $M_{\mathrm{n}, \mathrm{PS}}$ ) were in the range of the theoretical molar masses whereas $M_{\mathrm{n}, \mathrm{MALLS}}$ are systematically higher. Moreover, the poly(alkyl acrylate) diblock copolymer exhibit broad molar mass distributions $(2.7<\nsupseteq<7.0)$. The significant differences in molar masses provided by conventional calibration and MALLS as well as high dispersity are likely due to chain transfer to polymer producing statistically branched polyacrylates ${ }^{64,65}$ and/or irreversible chain-chain termination reactions favoured at 
high monomer conversions. ${ }^{48}$ Indeed, poly(alkyl acrylate) are prone to intramolecular and intermolecular chain transfer reactions leading to short-chain branching (SCB) and long-chain branching (LCB) respectively. ${ }^{64,}{ }^{65}$ Branching induces polymer chain compaction compared to linear polymer of same molar mass. LCB lead to inaccuracy of molar masses determined by SEC as linear and branched polymer chains with different molar masses can co-elute at the same hydrodynamic volume inducing local dispersity. ${ }^{66,67}$

Synthesis of PAA- $b$-poly(alkyl acrylate) and P(AA-co-MRB)- $b$-poly(alkyl acrylate) block copolymers by RAFT-mediated emulsion PISA produced latex particles with hydrodynamic diameter $\left(D_{\mathrm{h}}\right)$ ranging from 75 to $105 \mathrm{~nm}$ and narrow particle size distribution (polydispersity values $<0.1$ ) (Fig. 5, Table 2 and Table S7 †).

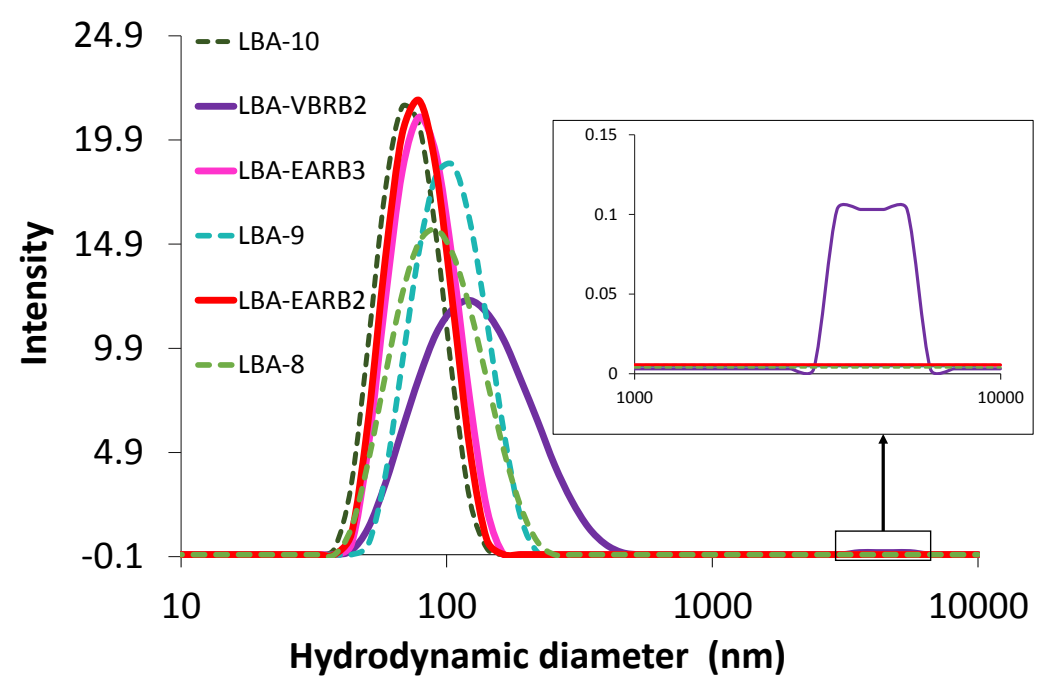

Fig. 5. Particle size distribution of waterborne latexes in water. Green dotted lines for PAA- $b$ $\mathrm{P} n \mathrm{BA}$ particles (see Table $\mathrm{S} 7 \dagger$ ) and plain lines correspond to RB-based latex: $-\mathrm{P}(\mathrm{AA}-\mathrm{co}-$ $\left.\mathrm{VBRB}_{0.1 \%}\right)-b-\mathrm{P} n \mathrm{BA}(L \mathrm{BA}-\mathrm{EARB} 2),-\mathrm{P}\left(\mathrm{AA}-c o-\mathrm{EARB}_{0.36}\right)-b-\mathrm{P} n \mathrm{BA}(L \mathrm{BA}-\mathrm{EARB} 3)$ and $\mathrm{P}\left(\mathrm{AA}-c o-\mathrm{VBRB}_{0.25}\right)-b$-P $n \mathrm{BA}(L \mathrm{BA}-\mathrm{VBRB} 2)$ (see Table 2$)$. Inset for higher $D_{\mathrm{h}}$ values. DLS measurements performed at $[$ Polymer $]=0.05$ g. $\mathrm{L}^{-1}$. 
The final number of particles $\left(N_{\mathrm{p}}\right)$ is comprised between $3.7 \times 10^{17}$ and $1.0 \times 10^{18}$ particles per liter of latex (Table 2 and Table S7 $\dagger$ ). Latexes are free of coagulum and aggregates except for the $\mathrm{P}\left(\mathrm{AA}-c o-\mathrm{VBRB}_{0.25 \%}\right)-b-\mathrm{P} n \mathrm{BA}$ diblock copolymer particles which contain 0.25 mol- $\%$ of the more hydrophobic VBRB comonomer in the outer shell (Fig. 5). Indeed, very few aggregates are observed for $\mathrm{P}\left(\mathrm{AA}-c o-\mathrm{VBRB}_{0.25 \%}\right)-b-\mathrm{P} n \mathrm{BA}$ latex together with higher polydispersity of 0.17 and an average $D_{\mathrm{h}}$ of $140 \mathrm{~nm}$ measured for the main population excluding the aggregates (non-linear least square method). It reveals a slight influence of increasing fraction of the more hydrophobic VBRB (see Fig. S21†) but still producing stable latex. Note that both series of RB-free and RB-based waterborne latexes are stable over 12 months of ageing (Fig. S22†).

Emulsion PISA for the synthesis of waterborne latex by route 2 (Scheme 1).

The main strategy of the present work as described in the upper section, involved the copolymerization of MRB with AA in order to take advantage of PISA to directly produce coreshell particles (Route 1 in Scheme 1). The location of the RB photosensitizer in the outer hydrophilic shell is expected to improve the interfacial energy transfer between oxygen and photosensitizer via a better vicinity. The diffusion length of ${ }^{1} \mathrm{O}_{2}$ is a compromise between its lifetime in a surrounding medium and its diffusion rate. At solid/liquid interface, it has been reported that singlet oxygen diffusion length is limited to several tens of nanometers, ${ }^{9,68}$ but as diameters of the waterborne latex synthesized in the present work are below $100 \mathrm{~nm}$, we attempted to design a second type of latex with the core functionalized by RB in order to investigate the effect of RB location on the quantum yield of singlet oxygen production. For that purpose, some latexes were synthesized by emulsion copolymerization of MRB and $n \mathrm{BA}$ mediated by $\mathrm{P}\left(\mathrm{A}^{-} \mathrm{NH}_{4}{ }^{+}\right)$-TTC macroCTA (Route 2 in Scheme 1). The P $n$ BA-based latexes were synthesized by emulsion PISA from PAA-TTC synthesized in DMSO (Table 3). 
It should also be mentioned that Route 1 facilitated the transportation of the hydrophobic MRB comonomer in the water phase via the hydrophilic poly(ammonium acrylate-co-MRB) stabilizer. For route 2, MRB was solubilized in $n$-butyl acrylate before the addition of water to circumvent the non-solubility of MRB powder monomer in water. Note that the MRB molar fraction of 0.1 mol- $\%$ corresponds to the molar fraction of MRB compared to PAA units in order to target similar range of final RB loading compared to latexes synthesized by route 1 (see experimental RB loadings in Table $\mathrm{S} 8 \dagger$ ). This corresponds to MRB concentration in $n \mathrm{BA}$ of $[\mathrm{MRB}]_{n \mathrm{BA}}=4.2 \times 10^{-4}$ mol.L $\mathrm{L}^{-1}$ (see Table S12 $\uparrow$ for the average range of solubility of VBRB in monomers). Stable monodisperse latex particles were recovered with hydrodynamic diameter and particle number in a range comparable to $\mathrm{P}(\mathrm{AA}-c o-\mathrm{MRB})-b-\mathrm{P} n \mathrm{BA}$ latexes (Table 2 and Table 3). Blocking efficiency is not compromised by the copolymerization of MRB with $n \mathrm{BA}$ as shown by Fig. S23†. It can be however noticed that, conversely to route 1 for which the effective MRB copolymerization was proven by characterizing the low molar mass macroCTA (Fig. S13 †, Fig. S14 $\dagger$ ), it is too challenging to prove the effective copolymerization of MRB with $n \mathrm{BA}$ in emulsion polymerization (route 2 ) due to the extremely low molar fraction of MRB in the final block copolymer $(<0.006 \mathrm{~mol}-\%,<0.05 \mathrm{wt}-\%$ based on final polymer $)$ and the poor MRB water solubility hindering fully effective dialysis. Moreover, emulsion copolymerization of $n \mathrm{BA}$ with $\mathrm{VBRB}$ (route 2 in Scheme 1) is associated with long inhibition period of 6 hours and retardation of emulsion polymerization compared to the synthesis of $\mathrm{P}\left(\mathrm{AA}-\mathrm{co}-\mathrm{VBRB} \mathrm{B}_{0.1 \%}\right)$ $b$-P $n$ BA latex by route 1 (Fig $\mathrm{S} 24 \dagger$ ). As for AA/MRB copolymerization in 1,4-dioxane, emulsion copolymerization of EARB induces less retardation compared to VBRB (Fig S24 $\uparrow$ ). As intermediate conclusion, route 1 is a more relevant strategy to tune the synthesis of Rose Bengal-based latex. A further study beyond the scope of the present manuscript will investigate the detrimental impact of MRB located in the core on the properties of the films formed from the RB-based waterborne latexes. 
Spectroscopic and photochemical properties of RB-based waterborne latex particles.

The absorbance spectra of the series of RB-based waterborne latexes exhibit the characteristic absorbance of both the conjugated Rose Bengal moiety $(450-600 \mathrm{~nm})$ and the trithiocarbonate end group $(280-340 \mathrm{~nm})($ Fig. S25 †). The maximum absorbance of MRB moiety at $560-$ $570 \mathrm{~nm}$ was used to calculate the experimental loadings of MRB in the latex $(0.32-1.80 \mu \mathrm{mol} . \mathrm{g}-$ 1, Table S8 †), which were comparable to the theoretical loadings. The maximum absorbance of MRB located either in the shell or in the core is associated with a bathochromic shift (Fig. $\mathrm{S} 25 \dagger$, Table $\mathrm{S} 8 \dagger)$ relative to the free $\mathrm{RB}$ in water $(549 \mathrm{~nm})$. Also note that mixing $\mathrm{RB}$-free latex with $\mathrm{RB}\left(\lambda_{\max , \text { water }}=548 \mathrm{~nm}\right)$ or $\mathrm{P}\left(\mathrm{AA}-\mathrm{co}-\mathrm{EARB}_{0.1 \%}\right)-\mathrm{TTC}$ macroCTA $\left(\lambda_{\max , \text { water }}=564\right.$ $\mathrm{nm}$ ) did not induce any shift of the absorption maxima of these species (Fig. S25 †, Table S8 $\dagger$ ). It should be taken into account that the bathochromic shift of the maximum absorbance and emission wavelengths was observed at the early VBRB synthesis step as maxima of VBRB in ethanol $\left(\lambda_{\text {abs, max, } \mathrm{VBRB}}=559 \mathrm{~nm}, \lambda_{\mathrm{em}, \max , \mathrm{VBRB}}=573 \mathrm{~nm}\right)$ red-shifted relative to free $\mathrm{RB}$ in ethanol $\left(\lambda_{\text {abs, max; } \mathrm{RB}}=548 \mathrm{~nm}, \lambda_{\mathrm{em}, \max , \mathrm{RB}}=569 \mathrm{~nm}\right) .{ }^{16}$ The bathochromic shift of MRB moiety in the waterborne latex is slightly higher for MRB located in the apolar $\mathrm{P} n \mathrm{BA}$ core in comparison with MRB surrounded by the $\mathrm{P}\left(\mathrm{A}^{-} \mathrm{NH}_{4}^{+}\right)$shell (Table $\left.\mathrm{S} 8 \dagger\right)$. The MRB group is characterized by two absorbance bands (noted S1 at $\sim 520 \mathrm{~nm}$ and $\mathrm{S} 2$ at $\sim 548-560 \mathrm{~nm}$ in Fig. S25 $\dagger$ ). The values of S2/S1 intensity ratio between the two vibrational components of the MRB main band are given in Table $\mathrm{S} 8 \uparrow$. It was first checked that mixing free $\mathrm{RB}$ or $\mathrm{P}\left(\mathrm{AA}-\mathrm{co}-\mathrm{EARB}_{0.1 \%}\right)$-TTC macroCTA with PAA- $b-\mathrm{P} n \mathrm{BA}$ latex provided $\mathrm{S} 2 / \mathrm{S} 1$ ratio of 3.0 , similar to free $\mathrm{RB}$ in water. The lower $\mathrm{S} 2 / \mathrm{S} 1$ values for $\mathrm{RB}$-grafted latex $(\mathrm{S} 2 / \mathrm{S} 1=1.9-2.6$, Table $\mathrm{S} 8 \dagger)$ reflects an effect of the latex surrounding but with no particular trend for MRB located in the particle core or particle shell. More interestingly is the very good level of photoactivity of all the waterborne latexes covalently bonded with RB moiety. Indeed, the quantum yield of singlet oxygen 
production $\left(\Phi_{\Delta}\right)$, determined by an indirect method based on the photooxidation reaction of furfuryl alcohol (FFA) in water (see Supporting Information), of most of the RB-based latexes ranges between $0.57 \pm 0.06$ to $0.74 \pm 0.07$ (Fig. 6 and Table S8 $\dagger$ ). The low quantum yield of $\mathrm{P}\left(\mathrm{AA}-c o-\mathrm{EARB}_{0.1 \%}\right)-b-\mathrm{P}(n \mathrm{BA}-c o-\mathrm{EA}) L \mathrm{BAEA}-\mathrm{EARB} 1$ latex $\left(\Phi_{\Delta}=0.41\right)$ is an exception that is not explained. These values are close to the quantum yield of singlet oxygen production by free $\operatorname{RB}\left(\Phi_{\Delta}=0.76\right)$, which reveals a particularly high photoactivity of the supported photosensitizer. The $\Phi_{\Delta}$ value measured for the mixture of free RB and PAA- $b-\mathrm{P} n \mathrm{BA}$ waterborne latex $\left(\Phi_{\Delta}=0.74\right)$ very close to the one of free $R B\left(\Phi_{\Delta}=0.76\right)$ validates the methodology based on correction of contribution of light scattering effect on the absorbance spectra (see details in ESI and in Table S8 $\dagger$ ). The quantum yield of singlet oxygen corresponding to the ratio of the number of moles of produced singlet oxygen per moles of photon absorbed, it provides an absolute value of photosensitizer efficiency whatever its concentration. Fig. 6 shows that the efficiency of the supported RB is similar for the all range of MRB molar fraction (from 0.1 to 0.36 mol- $\%$ based on AA units) and for both EARB and VBRB comonomers. 


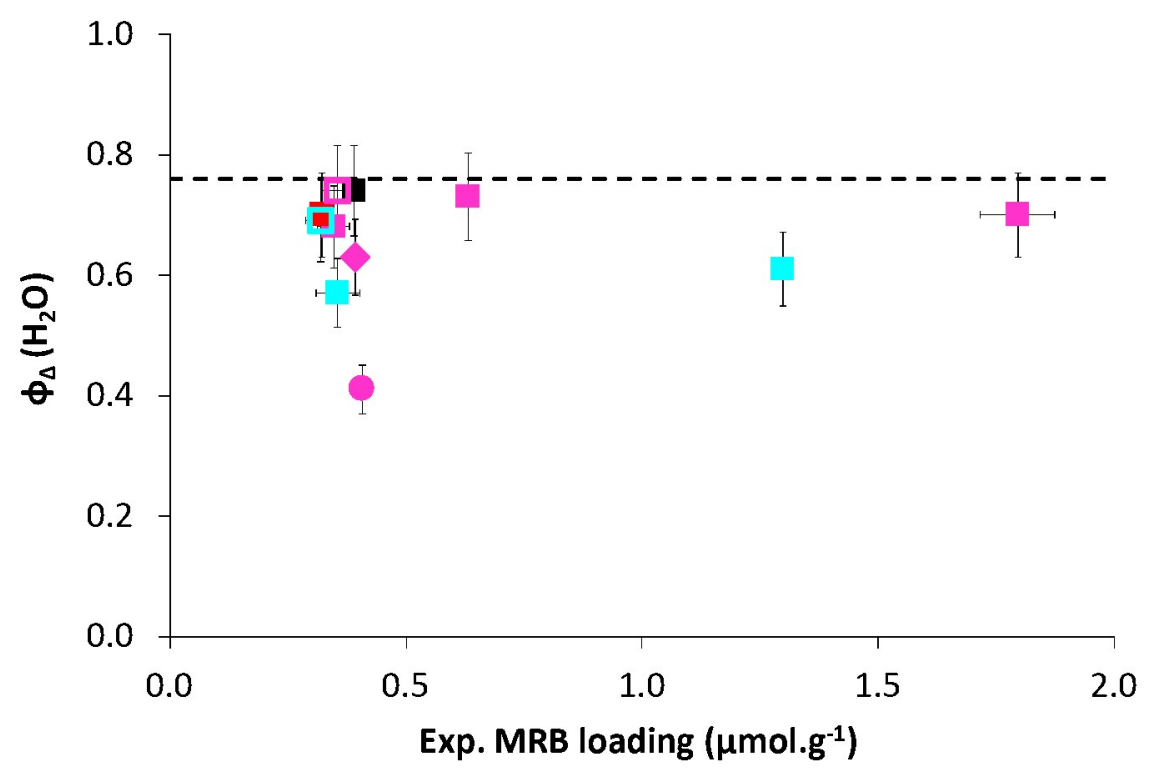

Fig. 6. Singlet oxygen production quantum yield versus experimental RB loading for latexes: P(AA-co-EARB)- $b$-P $n$ BA ( $L \mathrm{BA}-\mathrm{EARB} 1, L \mathrm{BA}-\mathrm{EARB} 2, L \mathrm{BA}-\mathrm{EARB} 3)$, $\square$ PAA- $b-\mathrm{P}(n \mathrm{BA}-$ $\left.c o-\mathrm{EARB}_{0.1 \%}\right)(L \mathrm{BA}-\mathrm{EARB} 5), \quad \mathrm{P}(\mathrm{AA}-c o-\mathrm{VBRB})-b-\mathrm{P} n \mathrm{BA}(L \mathrm{BA}-\mathrm{VBRB} 1, L \mathrm{BA}-\mathrm{VBRB} 2)$, PAA- $b-\mathrm{P}\left(n \mathrm{BA}-c o-\mathrm{VBRB}_{0.1 \%}\right)(L \mathrm{BA}-\mathrm{VBRB} 3), \diamond \mathrm{P}\left(\mathrm{AA}-c o-\mathrm{EARB}_{0.1 \%}\right)-b$-PEA $(L E A-E A R B 1)$, - P(AA-co-EARB $\left.\mathrm{E}_{0.1 \%}\right)-b-\mathrm{P}\left(n \mathrm{BA}_{70 \%}-c o-\mathrm{EA}_{30 \%}\right)(L \mathrm{BAEA}-\mathrm{EARB} 1)$, mixture of PAA- $b-\mathrm{P} n \mathrm{BA}$ (LBA-8) and RB, $\square$ mixture of PAA- $b-\mathrm{P} n \mathrm{BA}(L \mathrm{BA}-8)$ and $\mathrm{P}\left(\mathrm{AA}-c o-\mathrm{EARB}_{0.1 \%}\right)$-TTC (PAAEARB1). The dotted line represents the reference $\phi_{\Delta}$ value of RB. Error bars on experimental RB loading are determined from several measurements, error bars on $\phi_{\Delta}$ are estimated at $10 \%$.

The environmentally friendly emulsion PISA process produced photoactive core-shell particles with supported RB photosensitizer highly efficient at the water/colloid interface. The P(AA-coMRB)- $b$-poly(alkyl acrylate) block copolymers based on $n \mathrm{BA}, \mathrm{EA} / n \mathrm{BA}$ or EA exhibit glass transition temperature of the poly(alkyl acrylate) block ranging between $-45^{\circ} \mathrm{C}$ and $-12{ }^{\circ} \mathrm{C}$ (Table S9 †). These film-forming block copolymer polyacrylic latex pave the way to the preparation of photoactive polymer films/coating with tunable mechanical properties by simple casting of waterborne latex. The covalent bonding of Rose Bengal with the polymer colloids via straightforward copolymerization will confers strong anchorage of the organic photocatalyst with the polymer film, hence limiting any leaching or multi-step syntheses or use of halogenated solvent as previously reported to graft photosensitizer onto polymer surfaces. ${ }^{69-72}$ Film 
formation and characterization is beyond the scope of the present manuscript and will be the object of another subsequent study.

\section{Conclusion}

The RAFT polymerization of AA mediated by a trithiocarbonate chain transfer agent proved to be controlled at a close level in 1,4-dioxane, DMF and DMSO. The more polar DMSO solvent overcomes the retardation of AA polymerization observed in the presence of the MRB photosensitizer-based comonomer, especially for vinyl benzyl Rose Bengal compared to ethyl acrylate RB. High degree of chain end fidelity was observed for both PAA-TTC and P(AA-coMRB)-TTC. These well-defined hydrophilic macromolecular chain transfer agents were further involved in emulsion PISA to control the synthesis of stable and monodisperse block copolymer particles of diameter ranging between 85 and $100 \mathrm{~nm}$. The incorporation of 0.1 to $0.36 \mathrm{~mol}-\%$ of EARB or VBRB co-monomer with respect to AA units, either in the hydrophilic shell or in the hydrophobic core of nanoparticles slightly affected the polymerization kinetics. Complete monomer conversions were reached within a few hours for all latexes. The colloidal features of the series of latexes were not impacted by the MRB, except for the highest content of the more hydrophobic VBRB comonomer in the shell which produced latex with slightly higher size and dispersity. Emulsion PISA is a very efficient methodology to produce core-shell particle with the Rose Bengal photosensitizer straightforwardly anchored on the outer shell through the MRB-based reactive macromolecular stabilizer. The synthesized photoactive colloids are efficient in producing singlet oxygen at the water interface under visible light irradiation $\left(\lambda_{\text {LED }}\right.$ $=515 \mathrm{~nm})$ as the average quantum yield of singlet oxygen production $\left(\phi_{\Delta}=0.64 \pm 0.10\right)$ almost reach the level of free Rose Bengal $\left(\phi_{\Delta}=0.76 \pm 0.10\right)$. 


\section{Conflicts of interest}

There are no conflicts to declare.

\section{Acknowledgements}

The authors would like to thank Agence Nationale de la Recherche (ANR) for funding FUNPOLYSURF project and DLS equipment (ANR-15-CE08-0005-01), CNRS and UPPA for financial support. IPREM laboratory received funding from Equipex Xyloforest program (ANR-10-EQPX-16 XYLOFOREST) for NMR probe equipment. This manuscript is in honor of the $50^{\text {th }}$ anniversary of the French Polymer Group (Groupe Français des Polymères - GFP).

\section{References}

1. M. C. DeRosa and R. J. Crutchley, Coord. Chem. Rev., 2002, 233, 351-371.

2. M. L. Marin, L. Santos-Juanes, A. Arques, A. M. Amat and M. A. Miranda, Chemical Reviews, 2012, 112, 1710-1750.

3. A. A. Ghogare and A. Greer, Chemical Reviews, 2016, 116, 9994-10034.

4. S. Triemer, K. Gilmore, G. T. Vu, P. H. Seeberger and A. Seidel-Morgenstern, Angewandte Chemie International Edition in English, 2018, 57, 5525-5528.

5. E. Díez-Mato, F. C. Cortezón-Tamarit, S. Bogialli, D. García-Fresnadillo and M. D. Marazuela, Applied Catalysis B: Environmental, 2014, 160-161, 445-455.

6. F. Manjon, L. Villen, D. Garcia-Fresnadillo and G. Orellana, Environmental Science \& Technology, 2008, 42, 301-307.

7. Z. Zhou, J. Song, L. Nie and X. Chen, Chemical Society Reviews, 2016, 45, 6597-6626.

8. K. Page, M. Wilson and I. P. Parkin, Journal of Materials Chemistry, 2009, 19, 38193831 .

9. P. R. Ogilby, Chemical Society Reviews, 2010, 39, 3181-3209.

10. K. Zerdin, M. A. Horsham, R. Durham, P. Wormell and A. D. Scully, Reactive and Functional Polymers, 2009, 69, 821-827.

11. A. Beltrán, M. Mikhailov, M. N. Sokolov, V. Pérez-Laguna, A. Rezusta, M. J. Revillo and F. Galindo, Journal of Materials Chemistry B, 2016, 4, 5975-5979.

12. P. Sautrot-Ba, A. Contreras, S. A. Andaloussi, T. Coradin, C. Hélary, N. Razza, M. Sangermano, P.-E. Mazeran, J.-P. Malval and D.-L. Versace, Journal of Materials Chemistry B, 2017, 5, 7572-7582.

13. Lukasz Moczek and M. Nowakowska, Biomacromolecules, 2007, 8, 433-438.

14. S. Lacombe and T. Pigot, Catalysis Science \& Technology, 2016, 6, 1571-1592.

15. Y. Shiraishi, Y. Kimata, H. Koizumi and T. Hirai, Langmuir, 2008, 24, 9832-9836. 
16. L. Petrizza, M. Le Bechec, E. Decompte, H. El Hadri, S. Lacombe and M. Save, Polymer Chemistry, 2019, 10, 3170-3179.

17. C. T. J. Ferguson, N. Huber, K. Landfester and K. A. I. Zhang, Angew. Chem.-Int. Edit., 2019, 58, 10567-10571.

18. C. Boussiron, M. Le Bechec, L. Petrizza, J. Sabalot, S. Lacombe and M. Save, Macromolecular Rapid Communications, 2019, 40.

19. A. M. V. Herk, Blackwell Publishing, 2005.

20. F. D'Agosto, J. Rieger and M. Lansalot, Angew. Chem.-Int. Edit., 2020, 59, 8368-8392.

21. S. L. Canning, G. N. Smith and S. P. Armes, Macromolecules, 2016, 49, 1985-2001.

22. P. B. Zetterlund, S. C. Thickett, S. Perrier, E. Bourgeat-Lami and M. Lansalot, Chemical Reviews, 2015, 115, 9745-9800.

23. B. Charleux, G. Delaittre, J. Rieger and F. D’Agosto, Macromolecules, 2012, 45, 67536765.

24. N. J. W. Penfold, J. Yeow, C. Boyer and S. P. Armes, ACS Macro Lett., 2019, 8, 1029 1054.

25. J. Rosselgong, A. Blanazs, P. Chambon, M. Williams, M. Semsarilar, J. Madsen, G. Battaglia and S. P. Armes, ACS Macro Lett., 2012, 1, 1041-1045.

26. P. Gurnani, A. B. Cook, R. A. E. Richardson and S. Perrier, Polymer Chemistry, 2019, 10, 1452-1459.

27. S. Y. Khor, M. N. Vu, E. H. Pilkington, A. P. R. Johnston, M. R. Whittaker, J. F. Quinn, N. P. Truong and T. P. Davis, Small, 2018, 14, 13.

28. J. Lesage de la Haye, I. Martin-Fabiani, M. Schulz, J. L. Keddie, F. D’Agosto and M. Lansalot, Macromolecules, 2017, 50, 9315-9328.

29. M. Chenal, C. Vechambre, J. M. Chenal, L. Chazeau, V. Humblot, L. Bouteiller, C. Creton and J. Rieger, Polymer, 2017, 109, 187-196.

30. C. J. Ferguson, R. J. Hughes, B. T. T. Pham, B. S. Hawkett, R. G. Gilbert, A. K. Serelis and C. H. Such, Macromolecules, 2002, 35, 9243-9245.

31. N. S. Serkhacheva, N. I. Prokopov, E. V. Chernikova, E. Y. Kozhunova, I. O. Lebedeva and O. V. Borisov, Polymer International, 2019, 68, 1303-1314.

32. J. Zhou, R. He and J. Ma, Polymers, 2016, 8.

33. Z. Qiao, T. Qiu, W. Liu, L. Guo and X. Li, Polymer Chemistry, 2016, 7, 3993-3997.

34. C. St Thomas, R. Guerrero-Santos and F. D'Agosto, Polymer Chemistry, 2015, 6, 54055413.

35. E. V. Chernikova, A. V. Plutalova, K. O. Mineeva, I. R. Nasimova, E. Y. Kozhunova, A. V. Bol'shakova, A. V. Tolkachev, N. S. Serkhacheva, S. D. Zaitsev, N. I. Prokopov and A. B. Zezin, Polymer Science Series B, 2015, 57, 547-559.

36. X. Zhang, F. Boisson, O. Colombani, C. Chassenieux and B. Charleux, Macromolecules, 2013, 47, 51-60.

37. M. Chenal, J. Rieger, C. Vechambre, J. M. Chenal, L. Chazeau, C. Creton and L. Bouteiller, Macromol Rapid Commun, 2013, 34, 1524-1529.

38. D. E. Ganeva, E. Sprong, H. de Bruyn, G. G. Warr, C. H. Such and B. S. Hawkett, Macromolecules, 2007, 40, 6181-6189.

39. C. J. Ferguson, R. J. Hughes, D. Nguyen, B. T. T. Pham, R. G. Gilbert, A. K. Serelis, C. H. Such and B. S. Hawkett, Macromolecules, 2005, 38, 2191-2204.

40. O. J. Deane, O. M. Musa, A. Fernyhough and S. P. Armes, Macromolecules, 2020, 53, $1422-1434$.

41. G. Delaittre, J. Nicolas, C. Lefay, M. Save and B. Charleux, Chem. Commun., 2005, 5, 614-616.

42. G. Delaittre, J. Nicolas, C. Lefay, M. Save and B. Charleux, Soft Matter, 2006, 2, 223231. 
43. M. Gaborieau, R. Graf, S. Kahle, T. Pakula and H. W. Spiess, Macromolecules, 2007, 40, 6249-6256.

44. G. D. Airey and M. H. Mohammed, Rheologica Acta, 2008, 47, 751-763.

45. J. Chiefari, Y. K. Chong, F. Ercole, J. Krstina, J. Jeffery, T. P. T. Le, R. T. A. Mayadunne, G. F. Meijs, C. L. Moad, G. Moad, E. Rizzardo and S. H. Thang, Macromolecules, 1998, 31, 5559-5562.

46. C. Ladavière, N. Dörr and J. P. Claverie, Macromolecules, 2001, 34, 5370-5372.

47. J. Loiseau, N. Doërr, J. M. Suau, J. B. Egraz, M. F. Llauro, C. Ladavière and J. Claverie, Macromolecules, 2003, 36, 3066-3077.

48. M. Chenal, L. Bouteiller and J. Rieger, Polymer Chemistry, 2013, 4, 752-762.

49. J. T. Lai, D. Filla and R. Shea, Macromolecules, 2002, 35, 6754-6756.

50. J. Ji, L. Jia, L. Yan and P. R. Bangal, Journal of Macromolecular Science, Part A, 2010, 47, 445-451.

51. I. Chaduc, W. Zhang, J. Rieger, M. Lansalot, F. D'Agosto and B. Charleux, Macromolecular Rapid Communications, 2011, 32, 1270-1276.

52. L. Couvreur, C. Lefay, J. Belleney, B. Charleux, O. Guerret and S. Magnet, Macromolecules, 2003, 36, 8260-8267.

53. C. Reichardt, Chemical Reviews, 1994, 94, 2319-2358.

54. M. J. Kamlet, J. L. M. Abboud, M. H. Abraham and R. W. Taft, The Journal of Organic Chemistry, 1983, 48, 2877-2887.

55. A. Jeličić, N. García, H.-G. Löhmannsröben and S. Beuermann, Macromolecules, 2009, 42, 8801-8808.

56. M. Horn and K. Matyjaszewski, Macromolecules, 2013, 46, 3350-3357.

57. C. Wu, N. Corrigan, C. H. Lim, K. Jung, J. Zhu, G. Miyake, J. Xu and C. Boyer, Macromolecules, 2019, 52, 236-248.

58. E. L. Madruga, J. San Roman, M. A. Lavia and M. C. Fernandez-Monreal, European Polymer Journal, 1986, 22, 357-360.

59. U. Wendler, J. Bohrisch, W. Jaeger, G. Rother and H. Dautzenberg, Macromolecular Rapid Communications, 1998, 19, 185-192.

60. P. Lacroix-Desmazes, T. Delair, C. Pichot and B. Boutevin, Journal of Polymer Science Part A: Polymer Chemistry, 2000, 38, 3845-3854.

61. P. J. M. Stals, T. N. T. Phan, D. Gigmes, T. F. E. Paffen, E. W. Meijer and A. R. A. Palmans, Journal of Polymer Science Part A: Polymer Chemistry, 2012, 50, 780-791.

62. A. R. Maniego, A. T. Sutton, Y. Guillaneuf, C. Lefay, M. Destarac, C. M. Fellows, P. Castignolles and M. Gaborieau, Polymer Chemistry, 2019, 10, 2469-2476.

63. M. Chenal, J. Rieger, C. Vechambre, J. M. Chenal, L. Chazeau, C. Creton and L. Bouteiller, Macromolecular Rapid Communications, 2013, 34, 1524-1529.

64. N. M. Ahmad, D. Britton, F. Heatley and P. A. Lovell, Macromolecular Symposia, 1999, 143, 231-241.

65. N. Ballard and J. M. Asua, Progress in Polymer Science, 2018, 79, 40-60.

66. M. Gaborieau, J. Nicolas, M. Save, B. Charleux, J. P. Vairon, R. G. Gilbert and P. Castignolles, Journal of Chromatography A, 2008, 1190, 215-223.

67. M. Gaborieau and P. Castignolles, Anal Bioanal Chem, 2011, 399, 1413-1423.

68. C. Schweitzer and R. Schmidt, Chem Rev, 2003, 103, 1685-1758.

69. C. Piccirillo, S. Perni, J. Gil-Thomas, P. Prokopovich, M. Wilson, J. Pratten and I. P. Parkin, Journal of Materials Chemistry, 2009, 19, 6167-6171.

70. H. Hettegger, M. Gorfer, S. Sortino, A. Fraix, D. Bandian, C. Rohrer, W. Harreither, A. Potthast and T. Rosenau, Cellulose, 2015, 22, 3291-3304. 
71. W. J. Peveler, S. Noimark, H. Al-Azawi, G. B. Hwang, C. R. Crick, E. Allan, J. B. Edel, A. P. Ivanov, A. J. MacRobert and I. P. Parkin, ACS Applied Materials \& Interfaces, 2018, 10, 98-104.

72. L. Pessoni, S. Lacombe, L. Billon, R. Brown and M. Save, Langmuir, 2013, 29, 1026410271. 


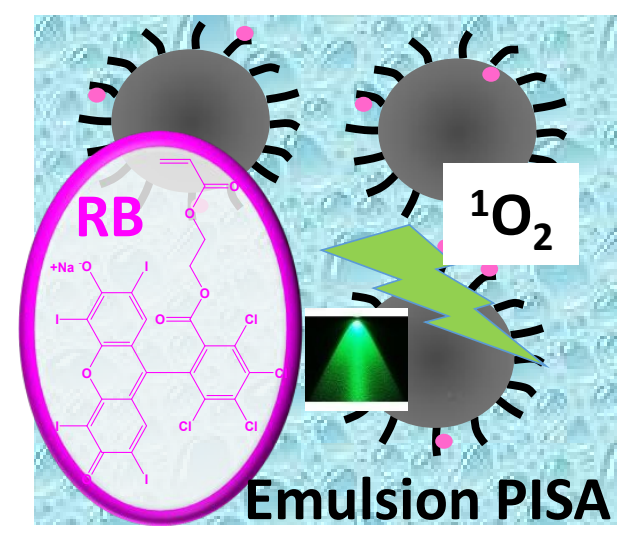

Rose Bengal shell- or core-functionalized acrylic latex synthesized by RAFT emulsion PISA: interfacial photosensitized ${ }^{1} \mathrm{O}_{2}$ production under visible light. 